Working Paper 10-32

Business Economic Series 06

July 2010
Departamento de Economía de la Empresa

Universidad Carlos III de Madrid

Calle Madrid, 126

28903 Getafe (Spain)

Fax (34-91) 6249607

\title{
How much should we pay for interconnecting electricity markets? A real options approach*
}

\author{
Álvaro Cartea ${ }^{1}$ and Carlos González-Pedraz ${ }^{1}$
}

\begin{abstract}
An interconnector is an asset that gives the owner the option to transmit electricity between two locations. In financial terms, the value of an interconnector is the same as a strip of real options written on the spread between power prices in two markets. We model the spread based on a: seasonal trend, mean-reverting Gaussian process, and mean-reverting jump process. We express the value of these real options in closed-form. We apply our valuation tool to five pairs of European neighboring markets to value a hypothetical one-year lease of the interconnector. We show valuations for different assumptions about the seasonal component of the spread, and different liquidity caps which proxy for the depth of the interconnected power markets. We derive no-arbitrage lower bounds for the value of the interconnector in terms of electricity futures contracts. We find that, depending on the depth of the market, the jumps in the spread can account for between $1 \%$ and $40 \%$ of the total value of the interconnector. The two markets where an interconnector would be most (resp. least) valuable are Germany and the Netherlands (resp. France and Germany).
\end{abstract}

Keywords: Real options, Bull Call Spread, interconnector, electricity prices, jumps, jump filter JEL Classification: G13, Q41

\footnotetext{
* This paper has benefited from comments of seminar participants at The University of Duisburg-Essen, Birkbeck-University of London, and Universidad Carlos III de Madrid. For comments and suggestions on earlier drafts, we are indebted to Peter E. George, Pablo Villaplana. E-mail addresses of the authors: Á. Cartea, alvaro.cartea@uc3m.es, and C. González-Pedraz, cugonzal@emp.uc3m.es.

${ }^{1}$ Department of Business Administration, Universidad Carlos III de Madrid.
} 


\title{
How much should we pay for interconnecting electricity markets? A real options approach*
}

\author{
Álvaro Cartea and Carlos González-Pedraz \\ Department of Business Administration, Universidad Carlos III de Madrid
}

28903 Getafe, Madrid, SPAIN.

Version: July 12, 2010

\begin{abstract}
An interconnector is an asset that gives the owner the option to transmit electricity between two locations. In financial terms, the value of an interconnector is the same as a strip of real options written on the spread between power prices in two markets. We model the spread based on a: seasonal trend, mean-reverting Gaussian process, and mean-reverting jump process. We express the value of these real options in closed-form. We apply our valuation tool to five pairs of European neighboring markets to value a hypothetical one-year lease of the interconnector. We show valuations for different assumptions about the seasonal component of the spread, and different liquidity caps which proxy for the depth of the interconnected power markets. We derive no-arbitrage lower bounds for the value of the interconnector in terms of electricity futures contracts. We find that, depending on the depth of the market, the jumps in the spread can account for between $1 \%$ and $40 \%$ of the total value of the interconnector. The two markets where an interconnector would be most (resp. least) valuable are Germany and the Netherlands (resp. France and Germany).
\end{abstract}

Keywords: Real options, Bull Call Spread, interconnector, electricity prices, jumps, jump filter JEL Classifications: G13, Q41

${ }^{*}$ This paper has benefited from comments of seminar participants at The University of Duisburg-Essen, Birkbeck-University of London, and Universidad Carlos III de Madrid. For comments and suggestions on earlier drafts, we are indebted to Peter E. George, Pablo Villaplana. E-mail addresses of the authors: Á. Cartea, alvaro.cartea@uc3m.es, and C. González-Pedraz, cugonzal@emp.uc3m.es. 


\section{Introduction}

Electricity markets have undergone a series of fundamental changes sparked by the liberalization of this industry. The first stage of liberalization required privatization of all or most of the generation assets, as well as privatization of the transmission grid which transports electricity from the generation points to the end consumer. Another important step in the development of the wholesale electricity markets is to exploit price differentials between locations by building interconnectors which are bi-directional transmission lines connecting the grids of two locations or the grids of two countries. Although interconnecting different grids is at the top of the political agenda in many countries, the decision to build them depends on their financial value. ${ }^{1}$

Electricity prices are characterized by exhibiting extreme volatility and by undergoing abrupt changes (large upward spikes and large downward jumps), as well as fast mean reversion to a seasonal trend. This extreme behavior is also present in the difference between prices of two locations and explains why interconnecting two markets could be profitable. The main question we address in this paper is how to value an interconnector. One of the key features that drives the financial value of an interconnector is that the owner has the right, but not the obligation, to transmit electricity between two locations. Therefore, once it has been built the financial value of an interconnector is given by a series of real options which are written on the price differential between two electricity markets.

In this paper we propose a valuation tool that uses real options theory to consider the problem and we employ market data of five pairs of European neighboring countries to value hypothetical interconnectors under realistic assumptions. The value of an interconnector is given by a strip of European-style options (Bull Call Spreads) written on the spread between the two markets and the valuation formula is in closedform and is quick to implement. Our model for the spread captures the main characteristics of the dynamics of price differentials: jumps in both directions, high seasonal volatility, and fast mean reversion to a seasonal trend. We propose an algorithm to detect jumps where the emphasis is placed on avoiding misclassifying mean reversion as jumps. We estimate the parameters of the spread model and find that the introduction of jumps in the model delivers gains in the in-sample performance of between $20 \%$ and $48 \%$.

We show valuations under different liquidity caps, which proxy for the depth of the interconnected power markets. We also derive no-arbitrage lower bounds for the value of the interconnector in terms of electricity futures contracts of the respective power markets. We find that most of the time these bounds are satisfied, but there are days where the value of the interconnector is given by the no-arbitrage bound instead of the price delivered by the sum of the prices of real options. We find that, depending on the depth of the market, the jumps in the spread can account for between $1 \%$ and $40 \%$ of the total value of the interconnector. The two markets where an interconnector would be most (resp. least) valuable are Germany and the Netherlands (resp. France and Germany). The markets where off-peak

\footnotetext{
${ }^{1}$ For example, see Department of Energy (2002) and European Commission (2008) for the policy steps towards interconnecting grids in the US and European Union.
} 
transmission between the two countries is more valuable than transmission during peak times are: France and Germany, France and UK, and the Netherlands and UK.

The rest of this paper is organized as follows. Section 2 reviews the literature on real options in commodity markets, electricity price models, and spread options. Section 3 discusses the data and why interconnectors are valuable. Section 4 frames the financial value of interconnector leases as a strip of European Bull Call Spread options and Section 5 derives no-arbitrage bounds for the lease based on traded assets such as electricity forwards and futures. Section 6 presents a model for the spread and derives valuation formulae. Section 7 describes how the model parameters are estimated and describes the algorithm that we propose to detect jumps and disentangle mean-reversion from jumps. Section 8 shows values of a one-year interconnection lease for five pairs of European neighboring markets and discusses the no-arbitrage bounds using futures data. Section 9 concludes.

\section{Literature Review}

In energy markets there are many projects whose value depends on the flexibility of being able to delay decision-making until more information becomes available. These decisions can include delaying or accelerating production, postponing entry, scaling production, changing technology, etc, see Trigeorgis (1996), Brennan and Trigeorgis (2000), and Keppo and Lu (2003). In many cases the flexibility embedded in some types of project is what drives most of their value. For example, some electricity plants are only economically viable to operate when market prices are very high, otherwise they must be "switched off". Moreover, gas-fired plants are very valuable because relative to other plants (for instance nuclear and coal) it is easier to ramp up or ramp down according to the level of market prices. Neglecting these embedded real options may seriously undervalue some projects to the extent that they might seem to deliver a negative NPV when in fact they are viable.

In the natural gas and liquified natural gas (LNG) industry, the value of some assets and financial instruments principally depends on the flexibility that these assets provide to their management. For example, the market value of a natural gas storage facility depends on the ability to store gas during times of low prices, and the ability to bring the stored gas to market at times of high prices, see Boogert and De Jong (2008), and Carmona and Ludkovski (2010). The value of natural gas supply contracts depends on the flexibility of the shipper to interrupt delivery during the life of the contract, see Jaillet, Ronn, and Tompaidis (2004), and Cartea and Williams (2008). Enders, Scheller-Wolf, and Secomandi (2010) consider the interaction between different types of real options that arise in natural gas production. In the LNG market, Lai, Wang, Kekre, Scheller-Wolf, and Secomandi (2010) discuss and value the real option of storing LNG at the downstream terminal of an LNG value chain.

Real options in electricity markets are also key components in project valuation. Power plants that offer operational flexibility derive most of their value from the option to produce electricity when prices are high. These options are valuable because wholesale electricity prices are extremely volatile, but the extreme behavior of power prices makes electricity prices a difficult commodity to model. Modeling 
electricity interruptible supply contracts and electricity swing contracts has been undertaken by Kamat and Oren (2002), Keppo (2004), and Hambly, Howison, and Kluge (2009). Modeling power prices, and other contracts such as futures and forwards, can be found in Lucía and Schwartz (2002), Roncoroni (2002), Cartea and Figueroa (2005), Weron (2006), Benth and Koekebakker (2008), Pirrong and Jermakyan (2008), Cartea and Villaplana (2008), Hikspoors and Jaimungal (2008), Borak and Weron (2008), Coulon and Howison (2009), and Kiesel, Schindlmayr, and Börger (2009).

The other literature that is relevant to our approach of valuing electricity interconnectors is that related to spread options. In this field, the first work on the valuation of the option to exchange one risky asset for another, i.e. the spread between two risky assets, is that of Margrabe (1978). Work on spread options in energy commodities can be found in Dempster, Medova, and Tang (2008), Hikspoors and Jaimungal (2007), Benth and Saltyte-Benth (2006), Marckhoff and Muck (2009b), Marckhoff and Muck (2009a), and for a thorough and extensive survey on the topic see Carmona and Durrleman (2003).

\section{The Market for Interconnectors and Data}

An important feature common to all energy commodities is that their market value depends on the location and the date that the delivery of the commodity takes place. This is particularly important for electricity where date and location are crucial determinants of market clearing prices because electricity must be consumed immediately upon delivery, while consumption of other energy commodities such as gas and oil can be deferred by either postponing delivery or by storing them. In fact, as a consequence of the non-storability of electricity, one can think of electricity delivered over different intervals of the day, or throughout periods of the year, as different goods. ${ }^{2}$

A further consequence of not being able to store electricity is that, strictly speaking, there are no electricity spot prices as commonly understood. Market clearing prices must be agreed prior to delivery at a time when production and demand are not known for sure; this uncertainty is resolved at the time when the physical transaction occurs. In addition, for this market clearing process to function, it is necessary for the system operator to ensure that there is sufficient capacity in the grid to secure transmission from generators to both retailers and consumers. Therefore, the convention in the market and the literature is to treat the day-ahead prices as the spot prices, although their structure is more akin to that of a forward contract. Depending on the market one can find different day-ahead quotes (prices today for next-day delivery) for contracts that dispatch electricity over fixed-time intervals during the delivery day. For example, in the UK it is possible to individually trade each of the 48 half-hours one day prior to delivery, while in the Nord Pool it is possible to individually trade each of the 24 hours one day prior to delivery. Another standard way in which blocks of electricity are bundled is peak and off-peak. Peak hours correspond to a fixed interval of hours for business days characterized by high electricity demand, normally between $8 \mathrm{am}$ and $8 \mathrm{pm}$. Off-peak hours belong to the interval between the end of a peak block and the beginning of the next one, and include the 24 hours of weekends' days and holidays. The day-

\footnotetext{
${ }^{2}$ Due to its non-storability, electricity is considered a non-traded asset, see Schwartz (1997).
} 
ahead peak and off-peak contracts specify delivery of $1 \mathrm{MWh}$ for every hour of their corresponding time interval.

The owner of the interconnector capacity needs to schedule the flows according to prevailing market prices and the transmission costs in the two interconnected locations. In practice these decisions are generally taken on the day-ahead market. Thus, we assume that the decision to use the interconnector to dispatch electricity from A to B, or vice versa, is based on the peak and off-peak market prices observed in the day-ahead market, net of transmission costs. Therefore, every day the owner of the interconnector capacity faces various alternatives. To commit to dispatching electricity the following day from A to B, or from B to A, during the peak and off-peak hours. To decide not to dispatch electricity in any direction during the peak and/or off-peak period.

\subsection{Data}

European energy markets are undergoing important changes in the way they function and in how integration between them is evolving. Bunn and Gianfreda (2010) employ electricity forward and spot data to show that the degree of market integration between the French, German, British, Dutch and Spanish markets is increasing. Here we look at five electricity markets: Powernext (France), UKPX (the United Kingdom), EEX (Germany and Austria), APX (the Netherlands) and Nord Pool (Norway, Sweden, Finland and Denmark). Table 1 summarizes the data we use in this paper. For all markets, peak and off-peak day-ahead prices for weekdays are available. In addition, for France, UK, and Nord Pool, we have data for weekends. The definition of peak hours differs across markets. For example, peak hours for France are between 9am and 8pm, Germany from 7am to 7pm, UK from 8am to 8pm, and Nord Pool from 7am to $10 \mathrm{pm}$.

Insert Table 1 about here

Panel A in Table 2 shows statistics for peak and off-peak prices for these five markets. We can see that mean prices across them can vary significantly. For example, in the Netherlands we find the highest mean peak prices, 58.77 Euros/MWh, and the lowest mean off-peak prices, 27.32 Euros/MWh.

Panel B in Table 2 hints at why interconnecting neighboring markets might be desirable. If we assume that transmission costs are around 5 Euros/MWh and if the price paid for interconnector capacity is seen as a sunk cost, then from a mean price point of view it would be profitable to transmit electricity across the different locations. For example, by looking at the mean of the historical spreads it seems that in the off-peak segment of the day it would be profitable to use the interconnector between France and the UK, and between the Netherlands and the UK. Similarly, in the peak segment, electricity would flow from Germany to Nord Pool, from the Netherlands to Germany, and from the UK to the Netherlands. However, we know that the volatility of the price spread will be a key determinant in the use of the interconnector; the more volatile the spread, the more likely it is that an interconnector will be used to take advantage of price discrepancies between two locations. 
As Table 2 shows, the correlation between the prices used to calculate the locational spreads in Panel $\mathrm{B}$ are in all cases significant and relatively high. Spreads range from a minimum of 0.33 for off-peak hours between Nord Pool and Germany, to a maximum of 0.85 for peak hours between France and Germany; two markets that are already partially interconnected.

We perform an Augmented Dickey-Fuller (ADF) test on the prices and spreads using 21 lags. Although the power of this type of test is sensitive to heteroscedasticity and outliers, statistics suggest the rejection of the unit root hypothesis in favor of mean-reverting alternatives in all cases. This pattern is even stronger for spread prices than for the price levels. The Jarque-Bera statistics in Table 2 show that spreads are far from being Gaussian. Moreover, spreads present a significant non-zero skewness and larger kurtosis than the prices.

Other important statistics shown in Panel B of Table 2 are the maxima and minima of the spreads. For example, the minimum peak spread between Germany and the Netherlands is -901 Euros/MWh. The maximum spread is between the Netherlands and UK at 915 Euros/MWh. Although these are the extreme cases observable in the data and although they are not frequent occurrences in these markets, it prompts a very important question. Will it be possible for the owner of the interconnector capacity to take simultaneous short and long positions in the two locations when the market is undergoing such remarkable price differentials? Although there seems to be insufficient public information about the depth of these markets, market participants agree that these represent situations where liquidity in at least one of the two locations is too thin. Consequently, it does not seem plausible to assume that the owner of the interconnector capacity will be able to take advantage of such extreme situations; something that will need to be taken into account when valuing the real option held by the owner of the interconnector capacity. We will return to this issue in Section 4 below.

Furthermore, in Panel A of Figure 1 we show peak prices for different locations, Panel B shows the peak spread between the different locations, Panel C shows off-peak prices, and Panel D the off-peak spread. In all these figures, we can observe the spiky behavior of prices and spreads, and the meanreversion property.

Insert Table 2 about here

Insert Figure 1 about here

\section{Valuing interconnection capacity: a strip of real options}

Writing contracts on the difference between two or more assets has a long tradition in commodity markets. In the exchanges, all of the commonly traded energy spread options have the difference between a linear combination of energy futures contracts as the underlying. These standard spread option contracts are written on the difference of futures contracts between: electricity and natural gas (the spark spread), electricity and coal (the dark spread), electricity and a fuel including emission allowance costs (the clean 
spread), crude oil and one of its derivative products (the crack spread), and others. ${ }^{3}$

We note that all energy spread options that are traded in exchanges have payoffs based on futures contracts. Consequently, models proposed in the literature to price options on spreads are designed to capture the stylized features of the underlying futures. Compared to more traditional asset classes such as equity, modeling commodities futures is relatively more involved due to the fact that energy futures have delivery periods (which can range from one day to years) rather than spot or instantaneous delivery, see Benth and Koekebakker (2008), Benth, Saltyte-Benth, and Koekebakker (2008), Fusai, Marena, and Roncoroni (2008), Borak and Weron (2008), and Fusai and Roncoroni (2008).

Our objective is to price the optionality provided by an interconnector that can exploit the wholesale electricity spot price differential between two markets. There are two crucial features that differentiate our problem from the more traditional spread options studied in the literature. First, for the owner of the interconnector capacity, the underlying "asset" of the real option is MWh of electricity and not futures or forwards written on electricity.

Second, the value of interconnection capacity between two locations, for instance locations A and $\mathrm{B}$, is equivalent to holding a strip of European-style options. The decision to use the interconnector to dispatch or not to dispatch electricity in any direction, at peak and off-peak hours, is based on the day-ahead market. That is, every day the owner of the interconnector exercises the right to use the capacity to simultaneously buy electricity in market $\mathrm{A}$, to sell the same quantity of electricity in market B, or vice versa. In other words, the owner of the capacity holds four daily European options: two options on the spread between A and B; and two options on the spread between B and A (one option for peak and the other for off-peak). Since each individual option is only for one day, we cannot cast the valuation problem in terms of futures contracts since the delivery period for these will be at least one month. Nevertheless the information provided by futures contracts can be used to determine no-arbitrage bounds for the European options on the spread; this is discussed in detail below in Section 5.

A further assumption we make is that the capacity of the interconnector is small relative to that of the markets it is connecting. This is the same as assuming that the presence of the interconnector does not alter the price dynamics in either market; a plausible assumption for the cases we study below. Although our model does not endogenize the impact that the interconnector might have on the spread dynamics, our framework allows us to analyze different scenarios and look at the sensitivity of the value of the interconnector to: price volatility; price spikes; speed of mean reversion; and liquidity constraints when two markets are interconnected. ${ }^{4}$

In Panel B of Table 2 we showed the maxima and minima of the spread for different locations and argued that in these extreme conditions markets were too thin; in Panels B and D of Figure 1 we can also appreciate some of the extreme prices in the spread. In at least one of the locations it does not seem plausible to take long or short positions at the prices that produced such large spreads. Here we assume that during times of extreme price deviations, the owner of the interconnector capacity can take

\footnotetext{
${ }^{3}$ See www.nymex.com for more information on the exchange traded spread options in energy commodities.

${ }^{4}$ Keppo and Lu (2003) consider the impact that market entry of a large electricity producer has on equilibrium prices.
} 
positions in both markets but we limit the extent to which he can profit from the situation. We do this by capping the amount of profit that can be extracted from in-the-money options upon exercise, when valuing interconnection capacity. We denote the maximum spread level, at which it is feasible for the owner of the interconnector capacity to take positions in both locations, by $M$ and for simplicity assume that this liquidity cap is the same regardless of whether it is an option on the peak or off-peak spread.

The valuation problem thus reduces to being able to price European capped options. For ease of presentation let us focus on the spread between A and B, which we denote $S^{\mathrm{A}, \mathrm{B}}(t)$, and assume that it is for peak electricity, without specifying the particular hour during the peak segment. Let $C_{p}^{\mathrm{A}, \mathrm{B}}\left(\min \left\{S^{\mathrm{A}, \mathrm{B}}(t), M\right\}, t ; T, K^{\mathrm{A}, \mathrm{B}}\right)$ denote the price of a European call at time $t$, written on the spread $S^{\mathrm{A}, \mathrm{B}}(t)$ during peak time, but capping the maximum value at $M>0$, and expiring at a future date $T$ with strike price $K^{\mathrm{A}, \mathrm{B}}<M$. The option gives the right to transmit $1 \mathrm{MWh}$ of electricity, during a designated hour of the day, but for ease of notation we do not specify the particular hour of the day. ${ }^{5}$ The strike price represents the transmission costs between locations A and B, and time $T$ represents the time in future periods when the decision will be made whether to use the interconnector capacity. Then, the price of the call is given by

$$
C_{p}^{\mathrm{A}, \mathrm{B}}\left(\min \left\{S^{\mathrm{A}, \mathrm{B}}(t), M\right\}, t ; T, K^{\mathrm{A}, \mathrm{B}}\right)=e^{-\rho(T-t)} \mathbb{E}_{t}\left[\max \left(\min \left\{S^{\mathrm{A}, \mathrm{B}}(T), M\right\}-K^{\mathrm{A}, \mathrm{B}}, 0\right)\right]
$$

where $\rho$ is the risk-adjusted discount rate, $\mathbb{E}_{t}$ denotes the expectation operator with information up until time $t, \max (a, b)$ denotes the maximum difference between the quantities $a$ and $b$, and $\min \{a, b\}$ denotes the minimum difference between the quantities $a$ and $b$.

The valuation problem of the capped European call (1) is also known in the literature as a Bull Call Spread. Note that capping the states of nature where the value of the call exceeds the cap $M$ is equivalent to being long a standard European call option with strike $K^{\mathrm{A}, \mathrm{B}}$ and short a standard European call option with strike $M$ written on the underlying $S^{\mathrm{A}, \mathrm{B}}(t)$. Hence

$$
C_{p}^{\mathrm{A}, \mathrm{B}}\left(\min \left\{S^{\mathrm{A}, \mathrm{B}}(t), M\right\}, t ; T, K^{\mathrm{A}, \mathrm{B}}\right)=C^{\mathrm{A}, \mathrm{B}}\left(S^{\mathrm{A}, \mathrm{B}}(t), t ; T, K^{\mathrm{A}, \mathrm{B}}\right)-C^{\mathrm{A}, \mathrm{B}}\left(S^{\mathrm{A}, \mathrm{B}}(t), t ; T, M\right),
$$

where the standard European call $C^{\prime}{ }^{\prime}\left(S^{\prime}{ }^{\prime}(t), t ; T, K^{\prime}{ }^{\prime}\right)=e^{-\rho(T-t)} \mathbb{E}_{t}\left[\max \left(S^{\prime},(T)-K^{\prime}, 0\right)\right]$, i.e. is given by equation (1) with $M=\infty$.

Generally, rights to interconnector capacity are sold over a period of time that covers a number of years and represents significant proportion of the life of the interconnection assets. For expository purposes we will assume that the rights are in the form of a one-year lease and we value a lease for capacity of $1 \mathrm{MWh}$ during peak times and $1 \mathrm{MWh}$ during off-peak times. The value of the interconnector lease is given by the sum of all the capped European call options (one for every day of transmission from A to B and from B to A) between time $t$ and expiry of the lease contract. Denoting by $V^{2 \text { hours }}(t)$ the value of the interconnector lease with $1 \mathrm{MWh}$ of capacity at time $t$ for one hour during peak and one

\footnotetext{
${ }^{5}$ If the peak time is 12 hours then the owner of the interconnector capacity holds 12 call options $C_{p}^{\mathrm{A}, \mathrm{B}}$ for the peak time and 12 options for the off-peak time $C_{o p}^{\mathrm{A}, \mathrm{B}}$ where the subscript $o p$ stands for off-peak.
} 
hour during off-peak we have that

$$
V^{2 \text { hours }}(t)=V^{\text {peak }}(t)+V^{\text {off-peak }}(t)
$$

where

$$
\begin{aligned}
V^{\text {peak }}(t) & =\sum_{i=1}^{365} C_{p}^{\mathrm{A}, \mathrm{B}}\left(\min \left\{S^{\mathrm{A}, \mathrm{B}}(t), M\right\}, t ; t+i / 365, K^{\mathrm{A}, \mathrm{B}}\right) \\
& +\sum_{i=1}^{365} C_{p}^{\mathrm{B}, \mathrm{A}}\left(\min \left\{S^{\mathrm{B}, \mathrm{A}}(t), M\right\}, t ; t+i / 365, K^{\mathrm{B}, \mathrm{A}}\right)
\end{aligned}
$$

is the value of the strip of peak real options, and

$$
\begin{aligned}
V^{\text {off-peak }}(t) & =\sum_{i=1}^{365} C_{o p}^{\mathrm{A}, \mathrm{B}}\left(\min \left\{S^{\mathrm{A}, \mathrm{B}}(t), M\right\}, t ; t+i / 365, K^{\mathrm{A}, \mathrm{B}}\right) \\
& +\sum_{i=1}^{365} C_{o p}^{\mathrm{B}, \mathrm{A}}\left(\min \left\{S^{\mathrm{B}, \mathrm{A}}(t), M\right\}, t ; t+i / 365, K^{\mathrm{B}, \mathrm{A}}\right)
\end{aligned}
$$

is the value of the strip of off-peak real options. Here the notations $C_{p}$ and $C_{o p}$ denote the capped calls on the peak and off-peak segments of every day respectively and the sum is from day 1 until day 365 . Hence the one-year lease consists of 1,460 options, of which 730 are for a one-hour slot during peak times and 730 are for a one-hour slot during off-peak times. ${ }^{6}$ Are the values (4), (5), (6) and (7) arbitrage free? We know that storing electricity in an economical way is not possible, therefore the four strips of 365 options described here cannot be arbitraged using a buy-and-hold argument. Below we show that by setting a simple strategy based on forward contracts, one can derive lower bounds for the four options discussed here.

\section{No-Arbitrage bounds}

Although the real option valuation of the interconnector requires knowledge of the distribution of the difference between peak and off-peak prices under the statistical measure and the risk-adjusted rate $\rho$ in order to discount the risky cash-flows, one can check whether the strip of call options being used in the valuation satisfies no-arbitrage lower bounds given by the forward or futures markets in both locations.

Assume that the lessor sells capacity for each hour of the day. For example, one can purchase interconnector capacity for the hour 8am to 9am for as many days as desired, or one can purchase the entire peak segment for as many days as desired. Now, let us focus on the no-arbitrage bound satisfied by interconnector capacity on peak electricity. Denote an electricity future for peak electricity in location $i=\{\mathrm{A}, \mathrm{B}\}$ by $F_{p}^{i}\left(t, T_{1}, T_{2}\right)$ where $t$ is the current time, $T_{1}$ is the expiry of the contract, delivery of electricity starts at time $T_{1}+1$, and $T_{2}$ is the last day of delivery. Below we show that at time $t$ the

\footnotetext{
${ }^{6}$ The value of a one-year lease for the 12 peak and 12 off-peak hourly slots of the day is given by $V^{24 \text { hours }}(t)=$ $12\left(V^{\text {peak }}(t)+V^{\text {off-peak }}(t)\right)$.
} 
price of interconnector capacity between dates $T_{1}+1$ and $T_{2}$, inclusive, must satisfy

$$
\sum_{j=T_{1}+1}^{T_{2}} C_{p}^{\mathrm{A}, \mathrm{B}}(t ; j)+C_{p}^{\mathrm{B}, \mathrm{A}}(t ; j) \geq \sum_{j=T_{1}+1}^{T_{2}} e^{-r(j-t)}\left(F_{p}^{\mathrm{B}}\left(t, T_{1}, T_{2}\right)-F_{p}^{\mathrm{A}}\left(t, T_{1}, T_{2}\right)-K^{\mathrm{A}, \mathrm{B}}\right)
$$

where $C_{p}^{\mathrm{A}, \mathrm{B}}(t ; j)=C_{p}^{\mathrm{A}, \mathrm{B}}\left(\min \left\{S^{\mathrm{A}, \mathrm{B}}(t), M\right\}, t ; T, K^{\mathrm{A}, \mathrm{B}}\right)$ and $C_{p}^{\mathrm{B}, \mathrm{A}}(t ; j)=C_{p}^{\mathrm{B}, \mathrm{A}}\left(\min \left\{S^{\mathrm{B}, \mathrm{A}}(t), M\right\}, t ; T, K^{\mathrm{B}, \mathrm{A}}\right)$ are the prices of the capped options at time $t$ that give the holder the right, but not the obligation, to use the interconnector to deliver $1 \mathrm{MWh}$ of peak electricity from location $\mathrm{A}$ to $\mathrm{B}$, or from $\mathrm{B}$ to $\mathrm{A}$, at time $T . r$ is the risk-free rate, and $K^{\mathrm{A}, \mathrm{B}}$ and $K^{\mathrm{B}, \mathrm{A}}$ are the transmission costs incurred when dispatching the 1 MWh of electricity.

Inequality (8) is a no-arbitrage bound because if it is not satisfied the following set of trades produces a riskless profit. First, assume that market quotes reveal that $F_{p}^{\mathrm{B}}\left(t, T_{1}, T_{2}\right)-F_{p}^{\mathrm{A}}\left(t, T_{1}, T_{2}\right)-K^{\mathrm{A}, \mathrm{B}}>0$; the interconnector capacity between locations A and B for peak electricity costs

$$
\sum_{j=T_{1}+1}^{T_{2}} C_{p}^{\mathrm{A}, \mathrm{B}}(t ; j)+C_{p}^{\mathrm{B}, \mathrm{A}}(t ; j)
$$

and inequality (8) is not satisfied. Second, pay (9) for the strip of calls on the interconnector capacity for the peak hours between $T_{1}+1$ and $T_{2}$ and, at the same time, go long a forward contract in location A and short a forward contract in location B (both with expiry $T_{1}$ and end of delivery $T_{2}$ for peak electricity). Every day, from $T_{1}+1$ to $T_{2}$, collect the $1 \mathrm{MWh}$ bought at price $F_{p}^{\mathrm{A}}\left(t, T_{1}, T_{2}\right)$ in location $\mathrm{A}$, send the power to B via the interconnector, sell it in B for $F_{p}^{\mathrm{B}}\left(t, T_{1}, T_{2}\right)$, and pay transmission charges of $K^{\mathrm{A}, \mathrm{B}}$. Therefore the present value of the net profits, where we include the cost of the interconnector capacity, is given by

$$
\sum_{j=T_{1}+1}^{T_{2}} \frac{\left(F_{p}^{\mathrm{B}}\left(t, T_{1}, T_{2}\right)-F_{p}^{\mathrm{A}}\left(t, T_{1}, T_{2}\right)-K^{\mathrm{A}, \mathrm{B}}\right)}{e^{r(j-t)}}-\sum_{j=T_{1}+1}^{T_{2}} C_{p}^{\mathrm{A}, \mathrm{B}}(t ; j)+C_{p}^{\mathrm{B}, \mathrm{A}}(t ; j)>0,
$$

which is greater than zero and represents a riskless profit, i.e. an arbitrage.

One of the points we clarify in the arbitrage strategy above is that although we assume that electricity is bought in market A and sold in market B, the arbitrageur's strategy requires him to purchase options to send peak electricity from both $\mathrm{A}$ to $\mathrm{B}$, and also from $\mathrm{B}$ to $\mathrm{A}$, even if he never transmits power from B to A. His arbitrage strategy commits him to using all the capacity every day during peak hours in only one direction, and the seller of the capacity charges the amount (9) regardless. This explains why we include the strip of options $\sum_{j=T_{1}+1}^{T_{2}} C_{p}^{\mathrm{B}, \mathrm{A}}(t ; j)$ as part of the cost of using the interconnector.

Therefore, given two peak forward contracts in locations A and B with the same $T_{1}$ and $T_{2}$, the following bounds must be obeyed for $t<T_{1}$ :

$$
\sum_{j=T_{1}+1}^{T_{2}} \frac{F_{p}^{\mathrm{B}}\left(t, T_{1}, T_{2}\right)-F_{p}^{\mathrm{A}}\left(t, T_{1}, T_{2}\right)-K^{\mathrm{A}, \mathrm{B}}}{e^{r(j-t)}} \leq \sum_{j=T_{1}+1}^{T_{2}} C_{p}^{\mathrm{A}, \mathrm{B}}(t ; j)+C_{p}^{\mathrm{B}, \mathrm{A}}(t ; j),
$$


and

$$
\sum_{j=T_{1}+1}^{T_{2}} \frac{F_{p}^{\mathrm{A}}\left(t, T_{1}, T_{2}\right)-F_{p}^{\mathrm{B}}\left(t, T_{1}, T_{2}\right)-K^{\mathrm{B}, \mathrm{A}}}{e^{r(j-t)}} \leq \sum_{j=T_{1}+1}^{T_{2}} C_{p}^{\mathrm{A}, \mathrm{B}}(t ; j)+C_{p}^{\mathrm{B}, \mathrm{A}}(t ; j),
$$

for peak hours.

Similarly, given off-peak forward contracts in locations A and B, the strip of off-peak real options must obey the following lower bounds:

$$
\sum_{j=T_{1}+1}^{T_{2}} \frac{F_{o p}^{\mathrm{B}}\left(t, T_{1}, T_{2}\right)-F_{o p}^{\mathrm{A}}\left(t, T_{1}, T_{2}\right)-K^{\mathrm{A}, \mathrm{B}}}{e^{r(j-t)}} \leq \sum_{j=T_{1}+1}^{T_{2}} C_{o p}^{\mathrm{A}, \mathrm{B}}(t ; j)+C_{o p}^{\mathrm{B}, \mathrm{A}}(t ; j),
$$

and

$$
\sum_{j=T_{1}+1}^{T_{2}} \frac{F_{o p}^{\mathrm{A}}\left(t, T_{1}, T_{2}\right)-F_{o p}^{\mathrm{B}}\left(t, T_{1}, T_{2}\right)-K^{\mathrm{B}, \mathrm{A}}}{e^{r(j-t)}} \leq \sum_{j=T_{1}+1}^{T_{2}} C_{o p}^{\mathrm{A}, \mathrm{B}}(t ; j)+C_{o p}^{\mathrm{B}, \mathrm{A}}(t ; j),
$$

where $C_{o p}^{\mathrm{A}, \mathrm{B}}(t ; j)=C_{o p}^{\mathrm{A}, \mathrm{B}}\left(\min \left\{S^{\mathrm{A}, \mathrm{B}}(t), M\right\}, t ; j, K^{\mathrm{A}, \mathrm{B}}\right)$ and $C_{o p}^{\mathrm{B}, \mathrm{A}}(t ; j)=C_{o p}^{\mathrm{B}, \mathrm{A}}\left(\min \left\{S^{\mathrm{B}, \mathrm{A}}(t), M\right\}, t ; j, K^{\mathrm{B}, \mathrm{A}}\right)$.

\section{A model for the electricity spot price differentials}

Modeling electricity prices, and other financial instruments related to this market, is quite recent in the academic literature. For instance, the work of Schwartz (1997) and Schwartz and Smith (2000) which considered storable commodities served as a platform for a number of articles that proposed no-arbitrage models for the dynamics of electricity prices, see Roncoroni (2010).

No-arbitrage spot price models. In the work of Lucía and Schwartz (2002) electricity prices are modeled according to non-observable state variables, where the stochastic element of the model is driven by two Brownian motions that account for the short-term movements and long-term trends in electricity prices. Cartea and Figueroa (2005) propose more general models where emphasis is placed on capturing the commonly observed large mean-reverting jumps.

Equilibrium and hybrid spot price models. Other models examined in the literature are the socalled equilibrium and hybrid models which, given the particular characteristics of electricity, explain price formation based on state variables that are mainly associated to supply and demand. This line of research has been pursued in Bessembinder and Lemmon (2002), Barlow (2002), Pirrong and Jermakyan (2008), and Cartea and Villaplana (2008), among others.

Since the valuation of the call options embedded in the interconnector capacity is cast within the real options framework, the emphasis must be placed on a model that is specified under the statistical measure. ${ }^{7}$ Here we propose a model in the spirit of the no-arbitrage spot price models which captures the most important features of the price dynamics, that is: large price spikes or jumps, strong mean reversion of large deviations and the presence of a seasonal component. In addition, our specification of

\footnotetext{
${ }^{7}$ Our model can also be employed to perform the valuation under a risk-neutral measure. This is achieved by choosing an equivalent martingale measure and calibrating the risk-neutral parameters to market data (usually futures or forward contracts). If the martingale measure preserves the same structure as the model we propose under the statistical measure, then the technique proposed below to value the interconnector as a real option can also be employed to value the interconnector under the risk-neutral measure.
} 
the model for electricity prices is such that when we look at the spread between two locations, we obtain the following three desired properties. First, the spread model also exhibits the stylized characteristics observed in the price difference between two locations, specifically large positive and negative deviations that mean revert very quickly to a seasonal trend. Second, the estimation of the spread model parameters can be achieved with the usual techniques. Third, the spread model specification enables us to calculate the price of European-style options by employing standard tools.

Although the main aim of the model is to value interconnector capacity, we also need it to explain how interconnector value depends on the stylized features of the spread dynamics. For example, it is important to be able to quantify how much value is due to: jumps in the spread under different liquidity assumptions, as captured by the cap $M$; the predictable seasonal component; and the volatility of the mean reverting Gaussian noise.

Hence for location $i=\{\mathrm{A}, \mathrm{B}\}$ we propose, under the statistical measure, the following arithmetic model for the electricity price $S^{i}(t)$ :

$$
S^{i}(t)=g^{i}(t)+X^{i}(t)+Y^{i}(t)
$$

where $g^{i}(t)$ is a deterministic seasonal pattern (i.e. the long term trend of the spot), $X^{i}(t)$ is a mean reverting stochastic process which satisfies the stochastic differential equation (SDE)

$$
d X^{i}(t)=-\alpha^{i} X^{i}(t) d t+\sigma^{i}(t) d W^{i}(t)
$$

and $Y^{i}(t)$ is a zero-mean reverting pure jump process with SDE

$$
d Y^{i}(t)=-\beta^{i} Y^{i}(t) d t+J^{i} d N^{i}(t)
$$

where $\alpha^{i}$ and $\beta^{i}$ are the speeds of mean reversion; $\sigma^{i}(t)$ is the time-dependent deterministic volatility; $d W^{i}(t)$ are the increments of a standard Brownian motion with $d W^{\mathrm{A}}(t) d W^{\mathrm{B}}(t)=\gamma d t ; N^{i}(t)$ denotes an inhomogeneous Poisson process with time-dependent intensity $\lambda^{i}(t)$, and $J^{i}$,s are i.i.d. shocks that represent the jump sizes in the price process. Moreover, we assume that the jump component $\sum^{N^{i}(t)} J^{i}$ is independent from $W^{\mathrm{A}}(t)$ and $W^{\mathrm{B}}(t)$ and that the $J^{i}$, s are independent from the counting processes $N^{i}(t)$.

Let $S^{\mathrm{A}, \mathrm{B}}(t)=S^{\mathrm{A}}(t)-S^{\mathrm{B}}(t)$ denote the spread in wholesale prices at time $t$ between locations $\mathrm{A}$ and B. Then the spread satisfies

$$
\begin{aligned}
d S^{\mathrm{A}, \mathrm{B}}(t)= & d S^{A}(t)-d S^{B}(t) \\
= & f^{\prime}(t) d t-\alpha^{A} X^{A}(t) d t+\alpha^{B} X^{B}(t) d t+\left(\sigma^{A}(t)-\sigma^{B}(t) \gamma\right) d W^{A}(t) \\
& -\sigma^{B}(t) \sqrt{1-\gamma^{2}} d \hat{W}(t)-\beta^{A} Y^{A}(t) d t+\beta^{B} Y^{B}(t) d t+J^{A} d N_{t}^{A}-J^{B} d N_{t}^{B},
\end{aligned}
$$


where $f^{\prime}(t)=\frac{d}{d t}\left(g^{\mathrm{A}}(t)-g^{\mathrm{B}}(t)\right), d W^{\mathrm{B}}(t)=\gamma d W^{\mathrm{A}}(t)+\sqrt{1-\gamma} d \hat{W}(t)$ and $\hat{W}(t)$ is a standard Brownian motion independent from $W^{\mathrm{A}}(t)$.

Instead of estimating the parameters for the two markets A and B, we can value the interconnector capacity by modeling the difference in prices directly. Therefore, we can estimate the parameters of model (18) and use it as the departure point to value the European call options on the spread. ${ }^{8}$ Before proceeding we can simplify the estimation procedure by assuming that $\alpha^{\mathrm{A}}=\alpha^{\mathrm{B}}=\alpha, \beta^{\mathrm{A}}=\beta^{\mathrm{B}}=\beta$ and letting

$$
\sigma^{2}(t)=\left(\sigma^{\mathrm{A}}(t)-\sigma^{\mathrm{B}}(t) \gamma\right)^{2}+\sigma^{\mathrm{B}}(t)^{2}\left(1-\gamma^{2}\right)
$$

Furthermore, for simplicity and without loss of generality we assume that we can model the positive jumps in location A and negative jumps in location B with $\Sigma^{N_{t}^{+}} J^{+}$, where $N_{t}^{+}$is an inhomogeneous Poisson counting process with time-dependent intensity $\lambda_{+}(t)$ and the positive jumps $J^{+}$are i.i.d.. Similarly, we assume that the negative jumps in location $\mathrm{A}$ and positive jumps in location $\mathrm{B}$ follow the process $\Sigma^{N_{t}^{-}} J^{-}$, where $N_{t}^{-}$is an inhomogeneous Poisson counting process with time-dependent intensity $\lambda_{-}(t)$ and the negative jumps $J^{-}$are i.i.d.. Hence, model (18) reduces to

$$
d S^{\mathrm{A}, \mathrm{B}}(t)=f^{\prime}(t) d t-\alpha X(t) d t+\sigma(t) d W(t)-\beta Y(t) d t+J^{+} d N_{t}^{+}-J^{-} d N_{t}^{-}
$$

where $X(t)=X^{\mathrm{A}}(t)-X^{\mathrm{B}}(t), Y(t)=Y^{\mathrm{A}}(t)-Y^{\mathrm{B}}(t), d W(t)$ are the increments of a standard Brownian motion and $W(t), N^{+}(t), N^{-}(t), J^{+}$and $J^{-}$are mutually independent.

Summarizing, we propose to model the spread at time $T$ between locations A and B as

$$
S^{\mathrm{A}, \mathrm{B}}(T)=f(T)+X(T)+Y(T)
$$

where

$$
\begin{gathered}
X(T)=X(t) e^{-\alpha(T-t)}+\int_{t}^{T} e^{-\alpha(T-u)} \sigma(u) d W(u), \\
Y(T)=Y(t) e^{-\beta(T-t)}+\int_{t}^{T} e^{-\beta(T-u)} J^{+} d N^{+}(u)+\int_{t}^{T} e^{-\beta(T-u)} J^{-} d N^{-}(u),
\end{gathered}
$$

and $f(T)$ is a deterministic seasonal component. The spread between B and $\mathrm{A}$ is given by $S^{\mathrm{B}, \mathrm{A}}(T)=$ $-S^{\mathrm{A}, \mathrm{B}}(T)$. Furthermore, below we assume that the jumps $J^{+}$and $J^{-}$are exponentially distributed.

\subsection{Call option with jumps}

In this subsection we describe how to price the real option (1) when the spread follows (21), with OU component (22), and jump component (23) with exponentially distributed jumps. The value of the call option is expressed in closed-form in Fourier space (see appendix for details). The value of a European-

\footnotetext{
${ }^{8}$ Modeling the spread directly can also be found in Benth and Saltyte-Benth (2006) and Benth and Kufakunesu (2009).
} 
style option to transmit electricity from market B to market A is given by evaluating

$$
C^{\mathrm{A}, \mathrm{B}}\left(S^{\mathrm{A}, \mathrm{B}}, t ; T, K^{\mathrm{A}, \mathrm{B}}\right)=\frac{e^{-r(T-t)}}{2 \pi} \int_{\infty+i \xi_{i}}^{\infty+i \xi_{i}} \Psi_{S}^{\mathrm{A}, \mathrm{B}}(-\xi) \Pi^{\mathrm{A}, \mathrm{B}}(\xi) d \xi
$$

where the transform variable $\xi=\xi_{r}+i \xi_{i}$, with $\xi_{r}, \xi_{i} \in \mathbb{R}, i=\sqrt{-1}$, and $\Pi^{\mathrm{A}, \mathrm{B}}(\xi)$ is the Fourier transform of the call option payoff between locations A and B:

$$
\Pi^{\mathrm{A}, \mathrm{B}}(\xi)=\int_{-\infty}^{\infty} e^{i \xi x} \max \left(x-K^{\mathrm{A}, \mathrm{B}}, 0\right) d x=-\frac{e^{i \xi K^{A, B}}}{\xi^{2}}, \quad \text { for } \quad \xi_{i}>0
$$

The other function that we need to calculate the inversion in (24) is the characteristic function of $S^{\mathrm{A}, \mathrm{B}}(T)$ :

$$
\begin{aligned}
\Psi_{S}^{\mathrm{A}, \mathrm{B}}(\xi):=\mathbb{E}\left[e^{i \xi S^{\mathrm{A}, \mathrm{B}}(T)}\right]= & e^{i \xi h(T)-\frac{1}{2} \xi^{2} \int_{t}^{T} e^{-2 \alpha(T-u)} \sigma^{2}(u) d u} \times e^{\int_{t}^{T}\left(\frac{\eta_{1}}{\eta_{1}-i \xi e^{-\beta(T-u)}}-1\right) \lambda^{+}(u) d u} \\
& \times e^{\int_{t}^{T}\left(\frac{\eta_{2}}{\eta_{2}+i \xi e^{-\beta(T-u)}}-1\right) \lambda^{-}(u) d u}
\end{aligned}
$$

where $h(T)=f(T)+X(t) e^{-\alpha(T-t)}+Y(t) e^{-\beta(T-t)}, \lambda^{+}(t)$ and $\lambda^{-}(t)$ are the time-dependent intensities of the Poisson arrival of positive and negative jumps respectively, and we require $-\eta_{2}<\xi_{i}<\eta_{1}$.

\subsection{Call option without jumps}

Since one of our objectives is to compare how the different factors that drive the spread dynamics affect the value of the interconnector, we are interested in the valuation of the interconnector when excluding jumps from the underlying price differential between the two markets. If we make the assumption that there are no jumps in the spread, the model becomes

$$
S^{\mathrm{A}, \mathrm{B}}(T)=f(T)+X^{n a i}(T)
$$

where

$$
X^{n a i}(T)=X^{n a i}(t) e^{-\alpha^{n a i}(T-t)}+\int_{t}^{T} e^{-\alpha^{n a i}(T-u)} \sigma^{n a i}(u) d W(u),
$$

and $f(T)$ is a deterministic seasonal component.

To price a call in this case we can proceed by evaluating (24), and keeping the valuation as before, but setting the jump intensities to zero in (26). Alternatively, we can use the fact that the spread is normally distributed and express the value of the call options in the following way.

The distribution of the spread at a future date is

$$
S^{\mathrm{A}, \mathrm{B}}(T) \sim N\left(\mu(t, T), v^{2}(t, T)\right)
$$


where

$$
\mu(t, T)=f(T)+X^{n a i}(t) e^{-\alpha^{n a i}(T-t)} \quad \text { and } \quad v^{2}(t, T)=\int_{t}^{T} e^{-2 \alpha^{n a i}(T-u)}\left(\sigma^{n a i}(u)\right)^{2} d u
$$

Let $\phi(x)$ and $\Phi(x)$ denote the probability and distribution functions of a standard normal random variable. Hence, the value of the capped European option to transmit electricity from location B to A is given by (see appendix for details)

$$
\begin{aligned}
C^{\mathrm{A}, \mathrm{B}}\left(\min \left\{S^{\mathrm{A}, \mathrm{B}}(t), M\right\}, t ; T, K^{\mathrm{A}, \mathrm{B}}\right)= & e^{-\rho(T-t)}\left[\mu(t, T)-K^{\mathrm{A}, \mathrm{B}}+v(t, T) \frac{\phi\left(\beta_{1}\right)}{1-\Phi\left(\beta_{1}\right)}\right] \Phi\left(-\beta_{1}\right) \\
& -e^{-\rho(T-t)}\left[\mu(t, T)-M+v(t, T) \frac{\phi\left(\beta_{2}\right)}{1-\Phi\left(\beta_{2}\right)}\right] \Phi\left(-\beta_{2}\right),
\end{aligned}
$$

where $\beta_{1}=\left(K^{\mathrm{A}, \mathrm{B}}-\mu(t, T)\right) / v(t, T), \beta_{2}=(M-\mu(t, T)) / v(t, T), K^{\mathrm{A}, \mathrm{B}}$ denotes transmission costs, from location $\mathrm{B}$ to $\mathrm{A}$ in Euros/MWh, and $M$ is the cap on the maximum spread that can be attained by the owner of the interconnector capacity.

Similarly, the price of a capped European call option on interconnector capacity, that gives the holder the right but not the obligation to transmit electricity from location $\mathrm{A}$ to $\mathrm{B}$, is given by

$$
\begin{aligned}
C^{\mathrm{B}, \mathrm{A}}\left(\min \left\{S^{\mathrm{B}, \mathrm{A}}(t), M\right\}, t ; T, K^{\mathrm{B}, \mathrm{A}}\right)= & -e^{-\rho(T-t)}\left[\mu(t, T)+K^{\mathrm{B}, \mathrm{A}}-v(t, T) \frac{\phi\left(\beta_{3}\right)}{\Phi\left(\beta_{3}\right)}\right] \Phi\left(\beta_{3}\right) \\
& +e^{-\rho(T-t)}\left[\mu(t, T)+M-v(t, T) \frac{\phi\left(\beta_{4}\right)}{\Phi\left(\beta_{4}\right)}\right] \Phi\left(\beta_{4}\right),
\end{aligned}
$$

where $\beta_{3}=\left(-K^{\mathrm{B}, \mathrm{A}}-\mu(t, T)\right) / v(t, T), \beta_{4}=(-M-\mu(t, T)) / v(t, T), K^{\mathrm{B}, \mathrm{A}}$ denotes transmission costs, from location $\mathrm{A}$ to $\mathrm{B}$, in Euros per MWh, and $M$ is the cap on the maximum spread that can be attained by the owner of the interconnector capacity.

\section{Estimation of model parameters}

In this section, we discuss how we estimate the underlying structural parameters of the state variables $X(t)$ and $Y(t)$, as well as the deterministic seasonal factor, $f(t)$. The estimation procedure requires the following steps. First, find the deterministic seasonal trend $f(t)$ using an OLS regression and compute the detrended spread. Second, detect the positive and negative jumps in the detrended spread series considering mean reversion in the jumps. The jump detection algorithm we employ is designed to cope with the problem of miss-identifying mean reversion as jumps. Third, find the MLE of the (possibly time-dependent) intensity of positive and negative jumps. Finally, estimate the parameters of the state variables $X(t)$ and $Y(t)$. 


\subsection{The model in discrete time}

Equations (21), (22) and (23) describe the continuous-time model for the spread $S^{\mathrm{A}, \mathrm{B}}(t)$ between locations $\mathrm{A}$ and $\mathrm{B}$. Recall that this model is given by a deterministic function $f(t)$ and two state variables which revert toward zero: an Ornstein-Uhlenbeck process $X(t)$ and a mean-reverting compound Poisson process $Y(t)$. We estimate the parameters of the discrete-time versions of the continuous-time equations (22) and (23) employing daily electricity data. For ease of notation we use time $t$ in subscript to denote the discrete version of the continuous time variables, for example the discrete versions of $X(t)$ and $Y(t)$ are denoted by $X_{t}$ and $Y_{t}$ respectively.

To estimate the parameters of the Gaussian process $X(t)$, we follow the approach in Bergstrom (1990) and use the following discrete model corresponding to equation (22)

$$
X_{t}=e^{-\alpha \Delta t} X_{t-\Delta t}+\varepsilon_{t} \quad t=1,2, \ldots, N
$$

where $\varepsilon_{t}$ satisfies

$$
\mathbb{E}\left[\varepsilon_{t}^{2}\right]=\sigma_{\varepsilon, t}^{2}=\frac{\sigma_{t}^{2}}{2 \alpha}\left(1-e^{-2 \alpha \Delta t}\right) \quad \text { and } \quad \mathbb{E}\left[\varepsilon_{t}\right]=0
$$

In a similar way to Das (2001), we specify the discrete-time version of the jump factor $Y(t)$ as

$$
Y_{t}=e^{-\beta \Delta t} Y_{t-\Delta t}+J^{+} \Delta N^{+}+J^{-} \Delta N^{-}
$$

Here $\Delta N^{+}$and $\Delta N^{+}$are the increments of the discrete-time counting process for positive and negative jumps with arrival frequency $\lambda_{t}^{+} \Delta t$ and $\lambda_{t}^{-} \Delta t$ and these can only take the values zero or one over the time-step $\Delta t$. The random variables $J^{+}$and $J^{-}$are positive and negative exponentially i.i.d. jump sizes with parameters $\eta_{+}$and $\eta_{-}$. In this case, the mean and variance of $J^{+}$and $J^{-}$are given by

$$
\mathbb{E}\left[J^{+}\right]=\frac{1}{\eta_{+}}, \quad \mathbb{E}\left[J^{-}\right]=\frac{1}{\eta_{-}} \quad \text { and } \quad \mathbb{V}\left[J^{+}\right]=\frac{1}{\eta_{+}^{2}}, \quad \mathbb{V}\left[J^{-}\right]=\frac{1}{\eta_{-}^{2}}
$$

We use these discrete schemes to estimate the set of parameters of the Gaussian, $\{\alpha, \sigma(t)\}$, and jump processes, $\left\{\beta, \lambda_{t}^{+}(t), \lambda_{t}^{-}(t), \eta^{+}, \eta^{-}\right\}$. Before determining these parameters, we proceed with the analysis of the seasonal behavior of spreads and prices.

\subsection{The deterministic function $f(t)$ and other seasonal features.}

As discussed previously we can interpret the dynamics of the spread $S^{\mathrm{A}, \mathrm{B}}(t)$ as a jump-diffusion process that reverts to a long-term trend, which in our model is captured by the time-dependent deterministic function $f(t)$. Although the seasonal component of electricity spreads has not been widely studied in the literature, the seasonal component of wholesale electricity prices has been in the spotlight for quite some time. For example, Lucía and Schwartz (2002) and Cartea and Villaplana (2008), among others, discuss the presence of a statistical and economically significant deterministic trend in spot prices that 
results from the seasonal characteristics which persist in these markets; one example being the strong seasonal pattern evidenced in the demand. Therefore, we expect the deterministic function $f(t)$ of the spreads to be directly linked to the difference between the deterministic factors captured by the seasonal components $g^{\mathrm{A}}(t)$ and $g^{\mathrm{B}}(t)$ of the wholesale prices in the two locations.

We follow the approach developed in Lucía and Schwartz (2002), Manoliu and Tompaidis (2002), and Jaillet, Ronn, and Tompaidis (2004) to model the seasonal component $f(t)$ of the spread of electricity spot prices. The discrete-time version of $f(t)$ takes the form:

$$
f_{t}=f_{0}+f_{1} t+\sum_{m=1}^{11} F_{m} D_{t}^{m}
$$

where $f_{0}$ is a constant, $f_{1}$ is the coefficient for the time trend, $F_{m}$, for $m=1, \ldots, 11$, are constant parameters and $D_{t}^{m}$ are monthly dummies taking the value 1 if $t$ belongs to the $m$ th month and 0 otherwise. ${ }^{9}$ Table 3 shows the estimates and Figure 2 depicts the seasonal function (37) for individual peak and off-peak prices and their corresponding spreads. Regarding the coefficients, the time trend is highly significant in all regressions, while the evidence of significance of monthly dummies is mixed. Although the same monthly coefficients are not significant for all markets and type of load, it seems that the coefficients for January to March, and May to July are significant for most of the cases considered.

The goodness of fit indicates that the seasonal factor is a key component in price levels. The $R^{2} \mathrm{~s}$ in Table 3 range from 0.09 for the peak prices of the Netherlands to 0.45 for the off-peak prices of France. On the other hand, the proportion of variability in spreads that is accounted for by the seasonal trend ranges from 0.01 (off-peak Germany and the Netherlands) to 0.17 (off-peak the Netherlands and UK).

\section{Insert Table 3 about here}

\section{Insert Figure 2 about here}

In the same way that vanilla call and put option prices are increasing in the volatility of their underlying, the value placed on the optionality provided by an interconnector to exploit price differentials between two locations is also increasing in the volatility of the spread. In the spread model the conditional variance of the discrete changes in the spread is given by

$$
\mathbb{V}\left[\Delta S_{t}^{\mathrm{A}, \mathrm{B}}\right]=\sigma_{\varepsilon, t}^{2} \Delta t+\lambda_{t}^{+} \Delta t \frac{1}{\eta_{1}^{2}}+\lambda_{t}^{-} \Delta t \frac{1}{\eta_{2}^{2}}
$$

One of the features that we explore is whether there is a seasonal pattern in the volatility of the spread innovations (38) which can emerge from a seasonal pattern in: the diffusion coefficient $\sigma_{\varepsilon, t}$ of the $X_{t}$ process; and/or the intensity of the jumps, $\lambda_{t}^{+}$and $\lambda_{t}^{-}$. To test for seasonality in the parameters that

\footnotetext{
${ }^{9}$ We tried other specifications for the seasonality. The alternatives we explored employed: seasonal dummies, instead of monthly ones; periodic continuous functions (sines and cosines), see Lucía and Schwartz (2002); or Fourier series as in Cartea and Figueroa (2005). We chose (37) because it has a high goodness-of-fit and, at the same time, it is intuitive and easy to interpret in the context of discrete-time estimations.
} 
drive the conditional variance, we assume a time-dependent seasonal functional form for the volatility $\sigma_{\varepsilon, t}$, and for the intensity parameters $\lambda_{t}^{+}$and $\lambda_{t}^{-}$.

In order for the number of parameters in the model to be tractable, and for us to have sufficient observations for each case, we model the periodicity with seasonal dummies as follows:

$$
\sigma_{\varepsilon, t}=\sigma_{\varepsilon, \text { winter }} \cdot D_{t}^{\text {winter }}+\sigma_{\varepsilon, \text { spring }} \cdot D_{t}^{\text {spring }}+\sigma_{\varepsilon, \text { summer }} \cdot D_{t}^{\text {summer }}+\sigma_{\varepsilon, \text { autumn }} \cdot D_{t}^{\text {autumn }}
$$

for the volatility, and

$$
\lambda_{t}^{+,-}=\lambda_{\text {winter }}^{+,-} \cdot D_{t}^{\text {winter }}+\lambda_{\text {spring }}^{+,-} \cdot D_{t}^{\text {spring }}+\lambda_{\text {summer }}^{+,-} \cdot D_{t}^{\text {summer }}+\lambda_{\text {autumn }}^{+,-} \cdot D_{t}^{\text {autumn }}
$$

for the intensity parameters of the positive and negative jumps. $D_{t}^{s}$ are seasonal dummies which take the values 0 or 1 . For example, if $s=$ winter, $D_{t}^{\text {winter }}$ takes value 1 if the observation is in December, January or February and 0 otherwise. Similarly, the dummies for the other seasons take values 0 or 1 . In the next section we show how to deal with these seasonal patterns in trend, volatility and intensity and their relation with the filtering of jumps and the estimation of the state-variables.

\subsection{Methodology to deal with the jump process and parameter estimates}

Here we discuss how to estimate the underlying structural parameters of the Gaussian variable $X(t)$ and the jump factor $Y(t)$ described by the discrete-time models (33) and (35). The estimation consists of six steps. First, remove the fitted seasonal component from the spread and calculate the detrended spread denoted by $\tilde{S}_{t}^{\mathrm{A}, \mathrm{B}}=S_{t}^{\mathrm{A}, \mathrm{B}}-f_{t}$. Second, detect the arrival of jumps (positive or negative) in the detrended spread series $\tilde{S}_{t}^{\mathrm{A}, \mathrm{B}}$ and avoid classifying fast mean-reversion as jumps. Third, estimate the jump intensities allowing for seasonal dependence in the arrival of the jumps. Fourth, estimate the parameters of the exponential distributions for positive and negative jumps. Finally, estimate the meanreversion rates of the Gaussian and jump factors of the spread model and the volatility of the Gaussian process. The first step is straightforward, we discuss the others below.

Detecting jumps. The approach we propose here is straightforward to implement. We apply a recursive semi-parametric filter to identify the calendar position of the jumps in the spread. The procedure identifies a hypothetical arrival of a jump when the detrended spread difference deviates, in absolute value, by more than three standard deviations from its mean, see for example Cartea and Figueroa (2005), and Benth, Saltyte-Benth, and Koekebakker (2008). These standard deviations might be time-dependent, so we compute them taking into account the possible seasonal pattern in the variance of the spread, see equation (39). We remove the observations identified as possible jumps, recalculate the mean, and proceed to filter again. We iterate until no jumps are found. However, in highly mean-reverting time series, for instance electricity prices, some of these hypothetical jumps could correspond to the mean-reversion effect and not to the arrival of jumps of opposite sign. As we can see in equation (35), the mean-reversion effect with rate $\beta$ is always present in the discrete-time dynamics of the jump process $Y_{t}$. 
Disentangling jumps from mean reversion. Our methodology is designed to cope with the problem of miss-identifying mean reversion as jumps as follows. Assume that at time $t$ spread prices are above the seasonal trend $S_{t}^{\mathrm{A}, \mathrm{B}}>f_{t} \cdot{ }^{10}$ Suppose that the next price innovation is negative, i.e. $S_{t+1}^{\mathrm{A}, \mathrm{B}}-S_{t}^{\mathrm{A}, \mathrm{B}}<0$, and that it is flagged as a possible jump because in absolute terms the innovation is larger than three standard deviations from the mean. Now, before labeling it as a downward jump, we check "how close" the new value $S_{t+1}^{\mathrm{A}, \mathrm{B}}$ is to $f_{t+1}$. If it is close to the seasonal component then it cannot be a downward jump, it must be mean reversion. If it is sufficiently below $f_{t+1}$, then it is a downward jump, that is, it diverges from the long-term trend. The metric used here to asses proximity to the seasonal trend is based on the confidence bounds around $f_{t}$. Spread prices that after a large negative innovation fall within $95 \%$ of the confidence bounds of the seasonal trend or above are not considered jumps, but are due to mean reversion. Only innovations that take the spread below the lower $95 \%$ confidence interval are considered a downward jump. Similarly, large upward shocks to the spread are considered positive jumps if they satisfy two requirements: the innovation is larger than three standard deviations from the mean; and the resulting spread at time $t+1$ is above the upper $95 \%$ confidence interval of the seasonal trend.

\section{Insert Figure 3 about here}

Estimating jump intensities. Once we have identified the jumps, we estimate their intensity by maximum likelihood. We analyze two scenarios, one where intensities are constant, and the other where intensities are time-dependent and may exhibit a seasonal pattern as described in equation (40). MLE results for the positive and negative intensities $\lambda^{+}(t)$ and $\lambda^{-}(t)$ for the spread are shown in Panel B of Table 4. In the table we also report the $p$-values of the likelihood ratio test, which compares the unrestricted model for the jump intensities (seasonal $\lambda^{+,-}(t)$ ) with the restricted model of constant intensities. $p$-values under 0.10 indicate rejection of the constant (restricted) model with a $10 \%$ significance level. In 16 out of 20 cases, we reject the model with constant intensity at a $10 \%$ significance level. For example, for peak spread between France and Germany, we reject the constant model in favor of a seasonal intensity for both positive (5\% significance) and negative jumps (10\% significance).

The jump detection algorithm proposed here is general in the sense that it can be applied to other price series such as spot price levels. We apply the filter to spot prices and report the estimates of intensities in Panel A of Table 4. In Figure 3, we show the positions of negative and positive jumps for each price and spread. Results of the likelihood ratio tests for spot prices are similar to those of the spreads. For price levels, positive jumps occur more frequently than negative ones which is in agreement with the positive skewness statistics reported in Table 2. The average number of positive and negative jumps per year ranges from 6 to 16. On the other hand, results in Panel B of Table 4 show that the estimated number of jumps for spreads ranges from 2 to 9 per year.

Note that there are more jumps in price levels than in the spread between two markets. This indicates that the arrival of jumps in neighboring markets may be correlated and lends support for a spread

\footnotetext{
${ }^{10}$ Here we use the spread $S_{t}^{\mathrm{A}, \mathrm{B}}$ in our example, but one can also employ the detrended time series $\tilde{S}_{t}^{\mathrm{A}, \mathrm{B}}$ where the only difference is that for the latter the mean is zero.
} 
model, as opposed to modeling levels and then taking the difference; in the spread model we circumvent the problem of capturing the correlation between the two locations. For example, in November 28 2005, there is a jump in the peak price in France (constant intensity $\lambda^{+}=7.4$ ) with size around 148 Euros/MWh. In that same day, the German peak price experiences a jump $\left(\lambda^{+}=7.6\right)$ of approximately 156 Euros/MWh. However, when we model the spread directly we do not detect a jump that day and the intensity of the positive jumps for the spread is $\lambda^{+}=6.0$. Another example can be found in December 132005 where the power peak price in the United Kingdom ( $\left.\lambda^{+}=10.8\right)$ jumps by 47 Euros/MWh. At the same time the peak price of the Netherlands $\left(\lambda^{+}=12.0\right)$ increases by 51 Euros/MWh, while we do not observe a jump in the spread $\left(\lambda^{+}=8.4\right)$ for that day.

\section{Insert Table 4 about here}

Estimating jump size parameters. One of the advantages of being able to locate jumps is that we also know their sizes and signages. We use this information to fit an exponential distribution to the jump data and to obtain the average sizes of positive and negative jumps given by $1 / \eta^{+}$and $1 / \eta^{-}$, where $\eta^{+}$and $\eta^{-}$are the parameters of the exponential distributions. The estimates are shown in Panel B of Table 5. The largest (lowest) parameter $1 / \eta^{+}$is 106 (28) which corresponds to the peak (off-peak) spread between Germany and the Netherlands (the Netherlands and UK). Similarly, the largest (lowest) parameter $1 / \eta^{-}$is 135 (33) which corresponds to the peak (off-peak) spread between Germany and the Netherlands (the Netherlands and UK). Finally for completeness, in Panel A of the same table we also report jump parameters for spot prices. This shows that for most markets the average size of the positive jumps is bigger than average size of the negative jumps, which agrees with the positive skewness statistics reported in Table 2.

Insert Table 5 about here

Estimating mean-reversion parameters and the volatility of the $\mathrm{OU}$ process. For each time series we estimate the mean-reversion rates of the Gaussian process $X_{t}$ and jump process $Y_{t}$, and the volatility parameters of $X_{t}$ by minimizing the mean-squared errors which are given by the average of the squared differences between the observed and the modeled spreads. We report the results in Table 5 where we see that price levels (Panel A) and spreads (Panel B) show significant mean reversion in jumps and in the Gaussian deviations. The half-life of the jumps ranges between 1 and 15 days approximately.

In Panel C of Table 5, we compute the in-sample mean of the difference between the absolute errors (MAE diff.) using a model where the spread is modeled directly, and the equivalent errors using a model where the price levels are modeled; the spread is obtained by taking the difference between the two models for the price level. Associated $p$-values are in parentheses and are corrected by autocorrelation up to 30 lags. This test of in-sample accuracy shows that the significant means are all positive, implying a better fit of the spread specification for most cases. There are some negative means (for example for off-peak spread between France and UK, and Nord Pool and Germany) but they are not significant. 
Below we compare the value of a one-year interconnector lease under different assumptions. As a specific case, we study one scenario where the spread is given by the seasonal component, and an OU process; i.e. when we do not include the jump process $Y(t)$ in the model. We label this valuation scenario as the "naive" version of the spread model because by simple inspection of the spread trajectories it seems implausible not to include a non-Gaussian factor in the spread model. The volatility of the OU process under the "naive" model might be seasonal and evolve following equation (39). We estimate the "naive" model with constant and seasonal volatility by maximizing the likelihood function. Table 6 shows the ML estimates for the "naive" model with these two types of volatility. Comparing the time-dependent specification of the variance with the constant one by the Bayesian information criteria (BIC), which penalizes the increase in the number of parameters, the hypothesis of seasonal variance for all spreads and prices is preferred. Only for the French-Germany spread market are the coefficients insignificant; maybe the pure Gaussian mean-reverting model for this spread is miss-specified.

In terms of in-sample performance, if we compare the root-mean-squared errors of the "naive" model with those of the jump-diffusion model, the introduction of jumps in the model delivers gains in the average performance of between $20 \%$ and $48 \%$.

Insert Table 6 about here

\section{The Market Value of Interconnectors}

In this section we discuss the results of valuing interconnection capacity in neighboring European countries. Based on the market data described above, we calculate the market value of a one-year lease of an interconnector that gives the lessee the right, but not the obligation, to transmit $1 \mathrm{MWh}$ of electricity between two markets during peak and off-peak times. The lease contract starts on January 12010 and ends on December 312010 and we assume that the initial condition of the OU and jump processes are both zero: $X(t)=Y(t)=0$ and $t=$ Jan 1 2010. We use the valuation formulae (4), (5), (6) and (7) to calculate prices for the four strips of options that total the value of the one-year lease of $1 \mathrm{MWh}$ capacity for a one-hour slot during peak time and a one-hour slot during off-peak time. We assume that the cash-flows are discounted at the risk-adjusted rate $\rho=10 \%$.

Initially we do not check whether the option values that we obtain are equal or above the no-arbitrage bounds derived in Section 5. We do this below in Subsection 8.1, where we calculate the lower bounds using futures data. Our assumption is that the lessor will price the real options and calculate the lower bounds (11), (12), (13) and (14), but for clarity we show the results of the option valuation first and then where necessary we amend the values in the light of the no-arbitrage bounds. ${ }^{11}$

We provide different values of the interconnector, which result from different assumptions about: the seasonal function of the spread; the liquidity and depth in both markets; and how jumps affect the

\footnotetext{
${ }^{11}$ If one or more lower bounds are not satisfied, the lessor will set the price according to the bound instead of the price indicated by the value of the strip of options. Alternatively, if a bound is not satisfied, one expects that market participants will bid the price of the lease up until the price reaches the no-arbitrage bound.
} 
extrinsic value of the real options used to calculate the value of the interconnector. We discuss how these three assumptions affect the value of the interconnector:

Seasonal component. One of the points that we scrutinize is how the seasonal component affects the value of the interconnector. In this paper we have assumed that the seasonal component is deterministic and that the historical seasonal trend will repeat itself at future dates when forecasting the spread. Although this assumption is consistent with that of the literature, care must be taken when producing forecasts and pricing options written on electricity price spreads. Indeed, inspecting Figure 2 prompts the question of whether it is plausible to expect that the seasonal component will in the future be broadly the same as it was in the past. The answer is probably not, but until now there has been no better alternative in the literature. ${ }^{12}$ Therefore, to appreciate the contribution of the seasonal component to the value of the interconnector, we look at different scenarios where we assume that for future dates the seasonal component is as in Figure 2, and for comparative purposes we also assume that the seasonal component is $f(T)=0$ for all $T$. To assume that the seasonal trend is zero is an extreme case because the markets that we are considering have their idiosyncrasies and this makes it reasonable to expect predictable patterns in the average price differentials between them. This is one of the reasons that incentivizes the integration between different locations, Bunn and Gianfreda (2010)

Liquidity constraints. We value the interconnector one-year lease under different assumptions of liquidity. As discussed above, it does not seem plausible to exploit large price differentials due to liquidity reasons in the two markets. We cap the maximum price differentials that can be profited from at different levels: $M \in\{10,20,30,50, \infty\}$ Euros/MWh, where we allow $M=\infty$ to include the hypothetical case where there are no liquidity constraints in the day-ahead market; i.e. the lessee is able to take simultaneous positions in the two interconnected markets. In all examples we assume that the transmission costs from A to B, and from B to A, for both peak and off-peak times, are $K=5$ Euros/MWh.

Jumps and extrinsic value. Both the volatility of the OU component of the spread model and the jumps increase the value of the interconnector. We can isolate the contribution of the jumps to the value of the interconnector in two ways. First, we can estimate the model parameters and value the interconnector with the jumps in the spread and then compare it to the valuation obtained if we "switch off" the jump factor, by setting the jump intensities of the positive and negative jumps to zero. The second alternative assumes that the only random factor driving the spread is a Gaussian component, and we obtain the value of the interconnector using the seasonal trend $f(T)$ plus an OU process (this is the "naive" model mentioned above). This method assumes that there is no jump factor.

We address the three points discussed above (seasonal trend, liquidity constraints, and jumps) by looking at two valuation scenarios. The values of the two scenarios are reported in Tables 7 and 8 (Scenario 1) and Table 9 (Scenario 2). In the tables the values of the one year-lease are broken into the four options available to the manager of the lease: transmit electricity from A to B and from B

\footnotetext{
${ }^{12}$ One could argue that forward and futures contracts incorporate the market's expected seasonal component for electricity prices in the different markets. However, these contracts also include a risk-premium which could be substantial, and seasonal too, see Cartea and Villaplana (2008). Another alternative is to add an arithmetic Brownian motion to the seasonal component so that the future seasonal trend is noisy, see Schwartz and Smith (2000) and Cartea and Williams (2008).
} 
to A for both on-peak and off-peak segments of the day. Note that these values are for the use of the interconnector during the 365 days of the one-year lease. The total value of the lease is given by the sum of the four options.

Scenario 1. Here the benchmark model is one that captures a seasonal component, a mean reverting OU process, and a mean reverting jump process:

$$
S^{\mathrm{A}, \mathrm{B}}(T)=f(T)+X(T)+Y(T)
$$

with $X(T)$ and $Y(T)$ described above in (22) and (23). Recall that $S^{\mathrm{B}, \mathrm{A}}(T)=-S^{\mathrm{A}, \mathrm{B}}(T)$. We show the results in Tables 7 and 8 .

Table 7 shows the value of a one-year interconnector lease for both peak and off-peak use. In the first column we show the different assumptions for the value of the liquidity cap $M$. The second and third columns show values of the flow from one market to the other during peak time when the model includes the seasonal trend $f(T)$, the OU Gaussian shocks $X(T)$, and the jumps $Y(T)$. For example, if $M=10$ Euros/MWh, the value of the 365 options to send 1 MWh of peak electricity from Germany to France (France to Germany) during peak times is 601 Euros (251 Euros), and if the cap is $M=50$ the 365 options are worth 1,457 Euros (641 Euros). In the same table, columns 4 and 5, show the value of the interconnector for peak time if the jump intensities are set to zero. In this case, if $M=10$ Euros/MWh, the 365 options to send peak electricity from Germany to France (France to Germany) is 572 Euros (209 Euros), or if the cap is $M=50$ Euros/MWh the value of the options is 1,082 Euros (357 Euros). ${ }^{13}$ Hence, if we use this example as a proxy for the value added by the jumps, then the difference between columns 2 and 4 ( 3 and 5) indicates how much value can be extracted from using the interconnector when there are jumps in the spread between Germany and France during peak hours. Columns 6 through 9 can be interpreted in the same way, but they refer to the case when the electricity flows are during off peak hours.

Insert Table 7 about here

In Table 8 we investigate the case when the seasonal trend is set to zero for all $T$. The table gives an indication of what happens to the value of the interconnector if it is assumed that for future dates the parameters of the OU and jump component are the same, but that the deterministic seasonal trend of the spread between the locations is zero. By comparing these values to those of Table 7, we can see that the seasonal trend adds considerable value to the interconnector, especially for cases with high liquidity cap $M$. For example, if the spread is modeled with $f(T)+X(T)+Y(T)$, then the value of an interconnector between France and Germany is 6,252 Euros $(M=50$ Euros/MWh), but if we assume that the seasonal function is set to zero, $f(T)=0$, then the value drops to 5,904 Euros. ${ }^{14}$

Insert Table 8 about here

\footnotetext{
${ }^{13}$ These values are calculated employing equations (4) and (5), where location A is France and location B is Germany.

${ }^{14}$ These figures are obtained from adding up the values of the peak and off peak of the flows between Germany and France. Note that the lessee owns the four options: Germany to France, France to Germany during peak time as well as off-peak time.
} 
Scenario 2. The other scenario we explore is one where we assume that shocks to the spread dynamics are mean-reverting Gaussian (exclude the jumps). This naive approach allows us to compare the values obtained by a market participant, who assumes that jumps in spread dynamics are too infrequent and that the liquidity restrictions too severe, to values obtained by a market participant that includes jumps in the model, but that acknowledges the liquidity constraints. These values are shown in Table 9.

In this valuation exercise we assume that the so-called naive market participant estimates the model

$$
S^{\mathrm{A}, \mathrm{B}}(T)=f(T)+X^{n a i}(T)
$$

where $X^{n a i}(T)$ is given by (28) and the seasonal component $f(T)$ is the same as above.

Table 6 shows the parameter estimates for the OU process (28) which are different from the estimates shown in Table 5 and used in Scenario 1. As in Scenario 1 above, columns 2 and 3 in Table 9 show values for the flow from one market to the other during peak time, when the model includes both the seasonal trend $f(T)$, and the OU Gaussian shocks $X^{n a i}(T)$. For example, the value of the 365 options to send $1 \mathrm{MWh}$ of peak electricity from Germany to France (France to Germany) during peak times is 678 Euros (407 Euros) if the cap is $M=10$ Euros/MWh, or 2,095 Euros (1,199 Euros) if the liquidity cap is $M=50$ Euros/MWh. Columns 4 and 5 show the value of the interconnector for peak time if the seasonal component is set to zero. In this case, the option to send peak electricity from Germany to France (France to Germany) is 529 Euros (529 Euros) if the cap is $M=10$ Euros/MWh or 1,579 Euros/MWh $(1,579$ Euros/MWh) if $M=50$ Euros/MWh. ${ }^{15}$

\section{Insert Table 9 about here}

If we compare the total value of the options in Scenarios 1 and 2, we see that the model that incorporates jumps will sometimes deliver higher or lower market values for the lease of the contract when we compare it to the prices calculated by the naive investor, who models the deseasonalized spread using an OU process. This result shows that market participants could be misled if the wrong model is used. The fact that jumps are not incorporated in the model does not imply that the probability of exercising the option to transmit electricity is lower or that the model assumes that on average less money is made when the option is exercised. In fact, it could go either way because the OU process is "forced" to capture large upward and downward highly mean reverting spikes by dramatically increasing the volatility and mean reversion of the Gaussian shocks in the OU process.

\subsection{No-arbitrage bounds}

The values in Tables 7, 8, and 9 do not take into account the arbitrage bounds that forward or futures prices could impose on the valuation of the interconnector. In this subsection we use the prices shown in Table 7 for the benchmark model $S(T)=f(T)+X(T)+Y(T)$ in columns 2, 3 (peak) and columns 6 ,

\footnotetext{
${ }^{15}$ Note the option values are the same in both directions because the seasonal component is zero, the OU process is symmetric, and we have assumed that the initial condition is $X^{\text {nai }}(t)=0$.
} 
7 (off-peak) as a reference. For a fixed liquidity cap $M$, the no-arbitrage bounds require that the sum of the values in columns 2 and 3 obey the peak electricity bounds (11) and (12). Similarly, for a given cap $M$ the sum of values in columns 6 and 7 must obey the no-arbitrage bounds (13) and (14).

Insert Figure 4 about here

To verify whether the prices reported in the valuation tables are arbitrage-free, we look at a particular example. Recall that the values reported in the tables are for a one-year lease between January 12010 and December 312010 and that these values were calculated employing data that ended in June 2009. The no-arbitrage bounds will depend on the market data on the day the calculation is performed; here it can be any day between July 12009 and December 31 2009. Figure 4 shows the bounds for every day during this period for France and Germany, France and UK, and Nord Pool and Germany. We can observe that the bounds exhibit considerable variation over time. These pronounced changes in the bounds are a reflection of changes in futures prices due to changes in: market expectations, fuel prices, changes in risk-premia, weather predictions, etc.

Let us focus on peak electricity between France and Germany. If $M=20$, the price of a one-year lease of $1 \mathrm{MWh}$ capacity, for a one-hour slot during the peak time between Germany and France, is 1,603 Euros (1,136 Euros for transmission from Germany to France plus 467 Euros for transmission from France to Germany). On October 28 2009, yearly futures (delivering electricity during peak time throughout 2010) are trading at 77.63 Euros/MWh in France and 68.15 Euros/MWh in Germany. Now, consider the following strategy: 1) Purchasing the yearly forward in Germany and selling a yearly forward in France; 2) Purchasing interconnector capacity for 2010, during peak time at 1,603 Euros (4.40 Euros/MWh during 365 days, see Table 7); 3) Every day during 2010, transmit 1 MWh from Germany to France and pay transmission costs of 5 Euros/MWh. The net present value of this arbitrage strategy is 8 Euros. ${ }^{16}$ Therefore, the valuation in Table 7 does not satisfy the no-arbitrage bound and if the lessor is selling capacity on October 28 2009, he should increase the price from 1,603 Euros to at least 1,611. However, if the same arbitrage strategy is considered on October 28 2009, the bound is equal to 1,283 Euros which is below the value charged by the lessor and there are no opportunities to arbitrage the price.

\section{Conclusions}

In this paper we show how to value an electricity interconnector as an asset that gives the owner the optionality to manage electricity flows between two markets. In financial terms, the value of the interconnector is the same as a strip of real options written on the spread between the power prices of two markets. We model the spread prices based on a: seasonal trend, mean-reverting Gaussian process, and mean-reverting jump process.

\footnotetext{
${ }^{16}$ The risk-free rate employed in the calculations is $3 \%$. Note that this profit is for $1 \mathrm{MWh}$ but could be much more if we consider that an interconnector may have a capacity of $1000 \mathrm{MWh}$ (or more) and that there are 12 peak hourly slots every day. In this case the total profit becomes 96,000 Euros.
} 
As a first contribution, we express the value of these real options in closed-form in the presence of mean-reverting jumps processes. We also propose a methodology to detect jumps in the spread that addresses the possible miss-classification of mean reversion as jumps. We estimate the parameters of the spread model and find that the introduction of jumps in the model delivers gains in the in-sample performance of between $20 \%$ and $48 \%$.

We value a hypothetical one-year lease of the interconnector between five pairs of European neighboring markets. The total value of the lease is the sum of the premia of 1,460 (4 times 365) real options on the spread: 365 options to transmit electricity from market A to B during on-peak hours; 365 to transmit electricity from A to B during off-peak hours; and the same number for transmitting both on- and off-peak power from market B to A. We show valuations under different assumptions about the seasonal component of the spread and different liquidity caps, which proxy for the depth of the interconnected power markets.

Although we cast the problem in terms of real options, where the statistical distribution of the spread and the risk-adjusted discount rate are key ingredients in the valuation, we also derive no-arbitrage lower bounds for the value of the interconnector in terms of electricity futures contracts. We show that most of the time these bounds are satisfied, but there are days where the value of the interconnector is given by the no-arbitrage bound instead of the price delivered by the sum of the prices of real options.

Some of our valuation findings indicate that, depending on the depth of the market, the jumps in the spread can account for between $1 \%$ and $40 \%$ of the total value of the interconnector. The two markets where an interconnector would be most (least) valuable is between Germany and the Netherlands (between France and Germany). The markets where off-peak transmission between the two countries is more valuable than transmission during the peak times are: France and Germany, France and UK, and the Netherlands and UK. 


\section{References}

Barlow, M.T, 2002, A Diffusion Model for Electricity Prices, Mahtematical Finance 12, 287-298.

Benth, F.E., and S. Koekebakker, 2008, Stochastic modeling of financial electricity contracts, Energy Economics 30, 1116-1157.

Benth, F.E., and R. Kufakunesu, 2009, Pricing of exotic energy derivatives based on arithmetic spot models, International Journal of Theoretical and Applied Finance 12, 491-506.

Benth, F.E., and J. Saltyte-Benth, 2006, Analytical Approximation for the Price Dynamics of Spark Spread Options, Studies in Nonlinear Dynamics \& Econometrics 10, 1355-1355.

Benth, F.E., J. Saltyte-Benth, and S. Koekebakker, 2008, Stochastic Modeling of Electricity and Related Markets vol. 11 of Advanced Series on Statistical Science and Applied Probability. (World Scientific Singapore-New Jersey-London).

Bergstrom, A.R., 1990, Continuous Time Econometric Modelling. (Oxford University Press, Oxford).

Bessembinder, H., and M.L. Lemmon, 2002, Equilibrium Pricing and Optimal Hedging in Electricity Forward Markets, The Journal of Finance LVII, 1347-1382.

Boogert, A., and C. De Jong, 2008, Gas storage valuation using a Monte Carlo method, Journal of Derivatives $15,81-98$.

Borak, S., and R. Weron, 2008, A semiparametric factor model for electricity forward curve dynamics, Journal of Energy Markets 1, 3-16.

Brennan, M.J., and L. Trigeorgis, 2000, Project Flexibility, Agency, and Competition: New Developments in the Theory and Application of Real Options. (OUP Oxford) 1st edn.

Bunn, D.W., and A. Gianfreda, 2010, Integration and shock transmissions across European electricity forward markets, Energy Economics 32, 278 - 291.

Carmona, R., and V. Durrleman, 2003, Pricing and Hedging Spread Options, SIAM Review 45, 627-685.

Carmona, R., and M. Ludkovski, 2010, Valuation of energy storage: an optimal switching approach, Quantitative Finance 10, 359 - 374.

Cartea, Á., and M.G. Figueroa, 2005, Pricing in Electricity Markets: a Mean Reverting Jump Diffusion Model with Seasonality, Applied Mathematical Finance 12, 313-335.

Cartea, Á., and P. Villaplana, 2008, Spot price modeling and the valuation of electricity forward contracts: The role of demand and capacity, Journal of Banking \& Finance 32, 2502-2519.

Cartea, Á., and T. Williams, 2008, UK Gas Markets: the Market Price of Risk and Applications to Multiple Interruptible Supply Contracts, Energy Economics 30, 829-846.

Coulon, M., and S. Howison, 2009, Stochastic behaviour of the electricity bid stack: from fundamental drivers to power prices, Journal of Energy Markets 2, 29-69.

Das, S., 2001, The surprise element: Jumps in interest rates, Journal of Econometrics 106, 27-65. 
Dempster, M.A.H., E. Medova, and K. Tang, 2008, Long term spread option valuation and hedging, Journal of Banking \& Finance 32, 2530-2540.

Department of Energy, US., 2002, National Transmission Grid Study. (Secretary of Energy, Washington DC.).

Enders, P., A. Scheller-Wolf, and N. Secomandi, 2010, Interaction between Technology and Extraction Scaling Real Options in Natural Gas Production, IIE Transactions (Forthcoming).

European Commission, UE., 2008, Interconnecting Europe. New perspectives for trans-European energy networks. (Official Publications of the European Communities, Luxembourg).

Fusai, G., M. Marena, and A. Roncoroni, 2008, Analytical pricing of discretely monitored Asian-style options: Theory and application to commodity markets, Journal of Banking \& Finance 32, 20332045.

Fusai, G., and A. Roncoroni, 2008, Implementing Models in Quantitative Finance: Methods and Cases. (Springer-Verlag).

Hambly, B., S. Howison, and T. Kluge, 2009, Modelling spikes and pricing swing options in electricity markets, Quantitative Finance 9, 937-949.

Hikspoors, S, and S. Jaimungal, 2007, Energy Spot Price Models And Spread Options Pricing, International Journal of Theoretical and Applied Finance 10, 1111-1135.

Hikspoors, S., and S. Jaimungal, 2008, Asymptotic Pricing of Commodity Derivatives for Stochastic Volatility Spot Models, Applied Mathematical Finance 15, 449-477.

Jaillet, J., E.I. Ronn, and S. Tompaidis, 2004, Valuation of Commodity-Based Swing Options, Management Science 50, 909-921.

Kamat, R., and S.S. Oren, 2002, Exotic Options for Interruptible Electricity Supply Contracts, Operations Research 50, 835-850.

Keppo, J., 2004, Pricing of Electricity Swing Options, Journal of Derivatives 11, 26-43.

Keppo, J., and H. Lu, 2003, Real options and a large producer: the case of electricity markets, Energy Economics 25, $459-472$.

Kiesel, R., G. Schindlmayr, and R. Börger, 2009, A two-factor model for the electricity forward market, Quantitative Finance 9, 279 - 287.

Lai, G., M.X. Wang, S. Kekre, A. Scheller-Wolf, and N Secomandi, 2010, Valuation of the real option to store liquefied natural gas at a regasification terminal, Operations Research (forthcoming).

Lucía, J., and E.S. Schwartz, 2002, Electricity Prices and Power Derivatives: Evidence from the Nordic Power Exchange, Review of Derivatives Research 5, 5-50.

Manoliu, M., and S. Tompaidis, 2002, Energy futures prices: term structure models with Kalman filter estimation, Applied Mathematical Finance 9, 21-43. 
Marckhoff, J., and M. Muck, 2009a, Jump Risk Premia in Short-Term Spread Options: Evidence from the German Electricity Market, http://ssrn.com/paper=1403817.

Marckhoff, J., and M. Muck, 2009b, Locational Price Spreads and the Pricing of Contracts for Difference: Evidence from the Nordic Market, Energy Economics 31, 257-268.

Margrabe, W., 1978, The Value of an Option to Exchange One Asset for Another, The Journal of Finance $33,177-186$.

Pirrong, C., and M. Jermakyan, 2008, The price of power: The valuation of power and weather derivatives, Journal of Banking \& Finance 32, 2520-2529.

Roncoroni, A., 2002, A Class of Marked Point Processes for Modeling Electricity Prices, PhD Université Paris IX Dauphine.

Roncoroni, A., 2010, Commodity Price Models, Encyclopedia of Quantitative Finance.

Said, Said E., and David A. Dickey, 1984, Testing for Unit Roots in Autoregressive-Moving Average Models of Unknown Order, Biometrika 71, 599-607.

Schwartz, E.S., 1997, The Stochastic Behavior of commodity Prices: Implications for Valuation and Hedging, The Journal of Finance 52, 923-973.

Schwartz, E.S., and J.E. Smith, 2000, Short-term variations and long-term dynamics in commodity prices, Management Science 46, 893-911.

Trigeorgis, L., 1996, Real Options: Managerial Flexibility and Strategy in Resource Allocation. (MIT Press Cambridge, MA, USA) 1st edn.

Weron, R., 2006, Modeling and Forecasting Electricity Loads and Prices: A Statistical Approach. (John Wiley \& Sons Chichester, England) 1st edn. 


\section{Appendix: Proofs}

\section{A. Prices of Options on the Spread Call option with jumps}

\section{Call option with jumps in the spread}

To calculate European option prices using transform techniques we need the Fourier transform of the payoff of the option and the characteristic function (cf) of the process for the spread. We start from the result that for a Lévy process $L(t)$ and a deterministic function $h(t)$

$$
\mathbb{E}\left[e^{i \xi \int_{t}^{T} h(u) d L_{u}}\right]=e^{\int_{t}^{T} \Psi(h(u) \xi) d u}
$$

where the transform variable $\xi=\xi_{r}+i \xi_{i}$, with $\xi_{r}, \xi_{i} \in \mathbb{R}$ and $i=\sqrt{-1}$.

Hence, for a compound Poisson process with time-dependent intensity $\lambda(t)$ and $h(u)=e^{-\beta(T-u)}$

$$
\mathbb{E}\left[e^{i \xi \int_{t}^{T} h(u) J d N_{u}}\right]=e^{\int_{t}^{T}\left(\Psi_{J}\left(e^{-\beta(T-u)} \xi\right)-1\right) \lambda(u) d u}
$$

where $\Psi_{J}(\xi)$ is the cf of the jump random variable $J$.

In the particular case where jump sizes, positive and negative, are exponentially distributed with probability density functions (pdf) $\eta_{1} e^{-\eta_{1} j}, j>0$ and $\eta_{2} e^{\eta_{2 j} j}, j<0$ respectively, the cfs of the pdfs of the positive and negative jumps are

$$
\mathbb{E}\left[e^{i \xi J}\right]=\frac{\eta_{1}}{\eta_{1}-i \xi} \quad \text { with } \quad \xi_{i}>-\eta_{1}
$$

and

$$
\mathbb{E}\left[e^{i \xi J}\right]=\frac{\eta_{2}}{\eta_{2}+i \xi} \quad \text { with } \quad \xi_{i}<\eta_{2}
$$

Since we assume that the intensity parameters of the inhomogeneous Poisson processes are either constant or piecewise constant, we must calculate the integrals $\int_{t}^{T} \Psi_{J}\left(e^{-\beta(T-u)} \xi\right) d u$, over a time interval $(t, T]$, for the positive and negative jumps, respectively:

$$
\begin{aligned}
\int_{t}^{T}\left(\frac{\eta_{1}}{\eta_{1}-i \xi e^{-\beta(T-u)}}-1\right) d u & =-\left.\frac{1}{\beta} \ln \left(i \xi e^{-\beta(T-u)}-\eta_{1}\right)\right|_{t} ^{T} \\
& =\frac{1}{\beta} \ln \left(\frac{i \xi e^{-\beta(T-t)}-\eta_{1}}{i \xi-\eta_{1}}\right),
\end{aligned}
$$

and

$$
\begin{aligned}
\int_{t}^{T}\left(\frac{\eta_{2}}{\eta_{2}+i \xi e^{-\beta(T-u)}}-1\right) d u & =-\left.\frac{1}{\beta} \ln \left(i \xi e^{-\beta(T-u)}+\eta_{2}\right)\right|_{t} ^{T} \\
& =\frac{1}{\beta} \ln \left(\frac{i \xi e^{-\beta(T-t)}+\eta_{2}}{i \xi+\eta_{2}}\right) .
\end{aligned}
$$


Thus, the cf of $S^{\mathrm{A}, \mathrm{B}}(T)$, conditioned on information up until time $t$, and assuming constant intensity parameters for the jump processes between $(t, T]$, is given by

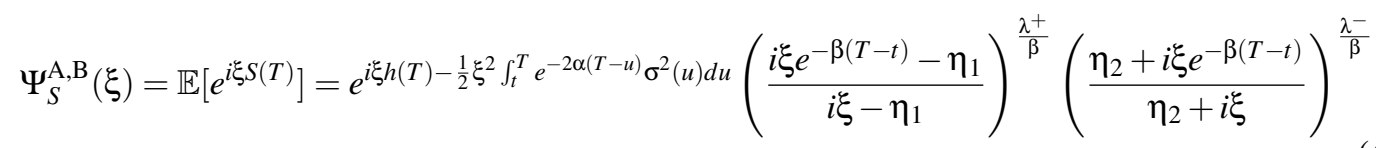

where $h(T)=f(T)+X(t) e^{-\alpha(T-t)}+Y(t) e^{-\beta(T-t)},-\eta_{1}<\xi_{i}<\eta_{2}$, and $\lambda^{+}$and $\lambda^{-}$are the intensities of the Poisson arrival of positive and negative jumps respectively.

Therefore, the price of European options on the spread $S^{\mathrm{A}, \mathrm{B}}(T)$, with expiry $T$ and strike $K^{\mathrm{A}, \mathrm{B}}$ is given by an integral along a straight line in $\mathbb{C}$ parallel to $\mathbb{R}$, where we are restricted to the strip $-\eta_{2}<\xi_{i}<\eta_{1}$

$$
C^{\mathrm{A}, \mathrm{B}}\left(S(t), t ; T, K^{\mathrm{A}, \mathrm{B}}\right)=\frac{e^{-r(T-t)}}{2 \pi} \int_{\infty+i \xi_{i}}^{\infty+i \xi_{i}} \Psi_{S}(-\xi) \Pi^{\mathrm{A}, \mathrm{B}}(\xi) d \xi
$$

and $\Pi^{\mathrm{A}, \mathrm{B}}(\xi)$ is the Fourier transform of the call option payoff:

$$
\Pi^{\mathrm{A}, \mathrm{B}}(\xi)=\int_{-\infty}^{\infty} e^{i \xi x} \max \left(x-K^{\mathrm{A}, \mathrm{B}}, 0\right) d x=-\frac{e^{i \xi K^{A, B}}}{\xi^{2}}
$$

for $\xi_{i}>0$. Furthermore to calculate the inversion in (42) we require $-\eta_{2}<\xi_{i}<\eta_{1}$. Similarly we obtain

$$
\Pi^{\mathrm{B}, \mathrm{A}}(\xi)=\int_{-\infty}^{\infty} e^{i \xi x} \max \left(-x-K^{\mathrm{B}, \mathrm{A}}, 0\right) d x=-\frac{e^{-i \xi K^{B, A}}}{\xi^{2}} \quad \text { for } \quad \xi_{i}<0
$$

\section{Proof of equations (31) and (32).}

Let $Y=S^{\mathrm{A}, \mathrm{B}}(T)$ and let $f(y)$ the pdf of the normal random variable $Y$ and recall that $\mu(t, T)$ and $v^{2}(t, T)$ are as in (30). Then $C^{\mathrm{A}, \mathrm{B}}\left(\min \left\{S^{\mathrm{A}, \mathrm{B}}(t), M\right\}, t ; T, K^{\mathrm{A}, \mathrm{B}}\right)$

$$
\begin{aligned}
& =e^{-\rho(T-t)}\left\{\int_{K^{\mathrm{A}, \mathrm{B}}}^{\infty} Y f(y) d y-K^{\mathrm{A}, \mathrm{B}} \int_{\beta_{1}}^{\infty} \phi(x) d x-\int_{M}^{\infty} Y f(y) d y-M \int_{\beta_{2}}^{\infty} \phi(x) d x\right\} \\
& =e^{-\rho(T-t)}\left\{\int_{K^{\mathrm{A}, \mathrm{B}}}^{\infty} Y f(y) d y-K^{\mathrm{A}, \mathrm{B}} \Phi\left(-\beta_{1}\right)-\int_{K^{\mathrm{A}, \mathrm{B}}}^{\infty} Y f(y) d y-M \Phi\left(-\beta_{2}\right)\right\} \\
& =e^{-\rho(T-t)}\left\{\left[\mu(t, T)-K^{\mathrm{A}, \mathrm{B}}+v(t, T) \frac{\phi\left(\beta_{1}\right)}{1-\Phi\left(\beta_{1}\right)}\right] \Phi\left(-\beta_{1}\right)-\left[\mu(t, T)-M+v(t, T) \frac{\phi\left(\beta_{2}\right)}{1-\Phi\left(\beta_{2}\right)}\right] \Phi\left(-\beta_{2}\right)\right\},
\end{aligned}
$$

where $\beta_{1}=\left(K^{\mathrm{A}, \mathrm{B}}-\mu(t, T)\right) / v(t, T), \beta_{2}=(M-\mu(t, T)) / v(t, T)$. To obtain (32) we proceed in a similar way.

Moreover, note that to evaluate the integrals that are of the form

$$
\int_{K^{\mathrm{A}, \mathrm{B}}}^{\infty} y f(y) d y
$$

in equation (45), where $f(y)$ is the pdf of the random variable $Y \sim N\left(\mu(t, T), v^{2}(t, T)\right)$, we use Bayes' 
theorem to obtain

$$
f(y)=f\left(y \mid y>K^{\mathrm{A}, \mathrm{B}}\right)\left(1-F\left(K^{\mathrm{A}, \mathrm{B}}\right)\right)
$$

where $F(y)$ is the distribution function of $Y$. Therefore

$$
\begin{aligned}
\int_{K^{\mathrm{A}, \mathrm{B}}}^{\infty} y f\left(y \mid y>K^{\mathrm{A}, \mathrm{B}}\right) d y & =\int_{K^{\mathrm{A}, \mathrm{B}}}^{\infty} y \frac{f(y)}{\left(1-F\left(K^{\mathrm{A}, \mathrm{B}}\right)\right)} d y \\
& =\frac{1}{\left(1-\Phi\left(K^{\mathrm{A}, \mathrm{B}}\right)\right)} \int_{K^{\mathrm{A}, \mathrm{B}}}^{\infty} y f(y) d y \\
& =\mu(t, T)+v(t, T) \frac{\phi\left(\left(K^{\mathrm{A}, \mathrm{B}}-\mu(t, T)\right) / v(t, T)\right)}{1-\Phi\left(\left(K^{\mathrm{A}, \mathrm{B}}-\mu(t, T)\right) / v(t, T)\right)}
\end{aligned}
$$

and for the last equality we use the fact that for a constant $K$

$$
\mathbb{E}[Y \mid K<Y]=\mu(t, T)+v(t, T) \frac{\phi((K-\mu(t, T)) / v(t, T))}{1-\Phi((K-\mu(t, T)) / v(t, T))}
$$

and

$$
\mathbb{E}[Y \mid Y<K]=\mu(t, T)-v(t, T) \frac{\phi((K-\mu(t, T)) / v(t, T))}{\Phi((K-\mu(t, T)) / v(t, T))} .
$$

Therefore, the truncated integral

$$
\begin{aligned}
\int_{K^{\mathrm{A}, \mathrm{B}}}^{\infty} y f(y) d y= & \mu(t, T)\left(1-\Phi\left(\left(K^{\mathrm{A}, \mathrm{B}}-\mu(t, T)\right) / v(t, T)\right)\right) \\
& +v(t, T) \frac{\phi\left(\left(K^{\mathrm{A}, \mathrm{B}}-\mu(t, T)\right) / v(t, T)\right)}{1-\Phi\left(\left(K^{\mathrm{A}, \mathrm{B}}-\mu(t, T)\right) / v(t, T)\right)}\left(1-\Phi\left(\left(K^{\mathrm{A}, \mathrm{B}}-\mu(t, T)\right) / v(t, T)\right)\right) .
\end{aligned}
$$

Similarly, in the proof of (32) we need to evaluate integrals of the form

$$
\begin{aligned}
\int_{-\infty}^{-K^{\mathrm{B}, \mathrm{A}}} y f(y) d y= & \left.\mu(t, T) \Phi\left(\left(-K^{\mathrm{B}, \mathrm{A}}-\mu(t, T)\right) / v(t, T)\right)\right) \\
& \left.+v(t, T) \frac{\phi\left(\left(-K^{\mathrm{B}, \mathrm{A}}-\mu(t, T)\right) / v(t, T)\right)}{1-\Phi\left(\left(-K^{\mathrm{B}, \mathrm{A}}-\mu(t, T)\right) / v(t, T)\right)} \Phi\left(\left(-K^{\mathrm{B}, \mathrm{A}}-\mu(t, T)\right) / v(t, T)\right)\right) .
\end{aligned}
$$


Table 1

\section{Five European Power Markets}

Summary of the data used throughout the article. We consider time series for the day-ahead price (also called system or spot price) traded in the physical market for five European exchange markets. For some markets we do not have access to prices for weekends or national holidays (Weekend $=$ No). If we have data for these days (Weekend $=$ Yes), we use it in the analysis.

\begin{tabular}{llccl}
\hline \hline Countries & Market & Period & \# obs. & Weekend \\
\hline France & Powernext & $26 / 11 / 2001-02 / 07 / 2009$ & 2,776 & Yes \\
Germany and Austria & EEX & $16 / 06 / 2000-01 / 07 / 2009$ & 2,359 & No \\
United Kingdom & UKPX & $01 / 01 / 2002-29 / 04 / 2009$ & 2,676 & Yes \\
Netherlands & APX & $03 / 01 / 2000-02 / 07 / 2009$ & 2,479 & No \\
Norway, Sweden, Finland and Denmark & Nord Pool & $01 / 01 / 2000-04 / 07 / 2009$ & 3,473 & Yes \\
\hline
\end{tabular}




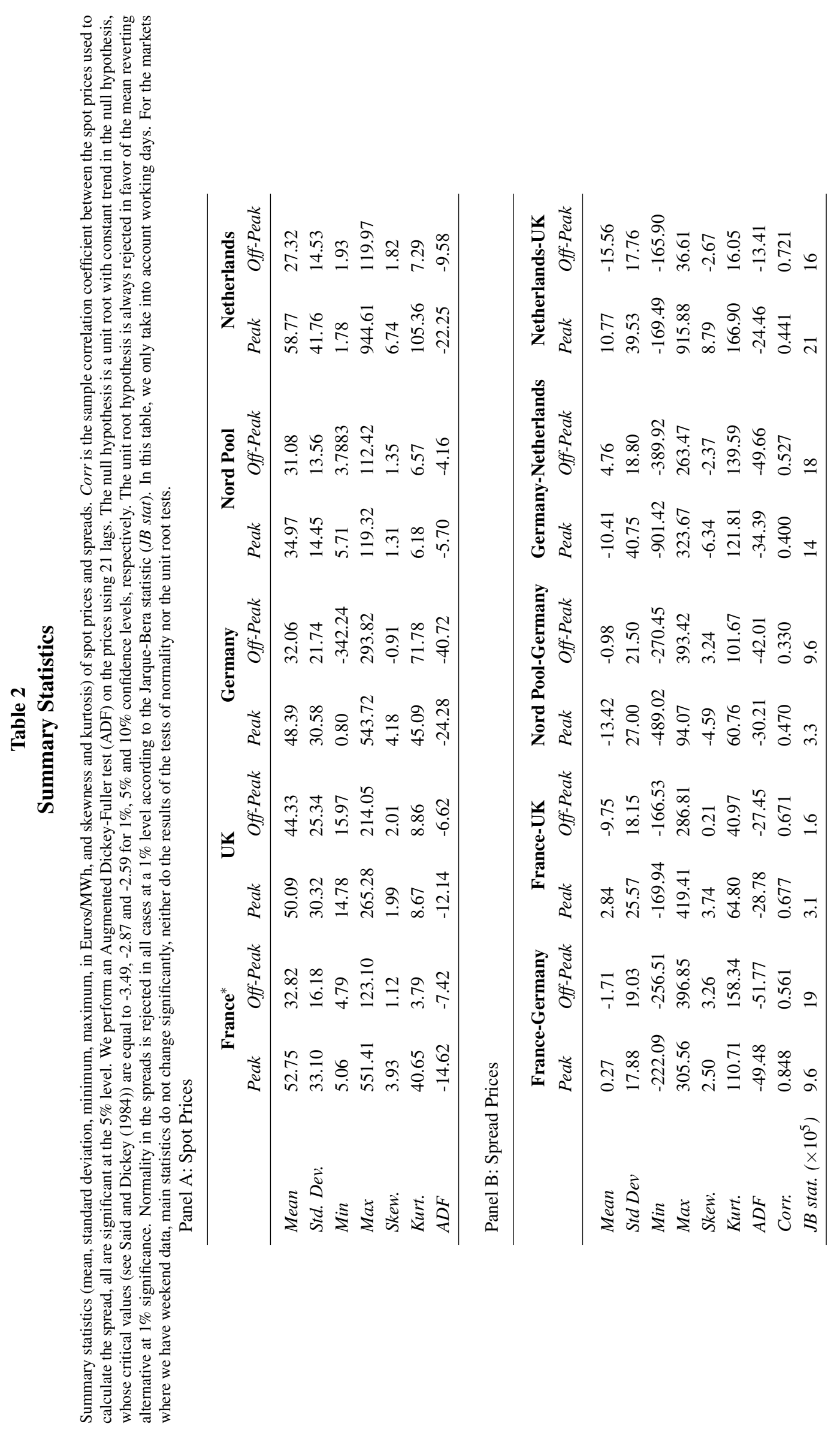




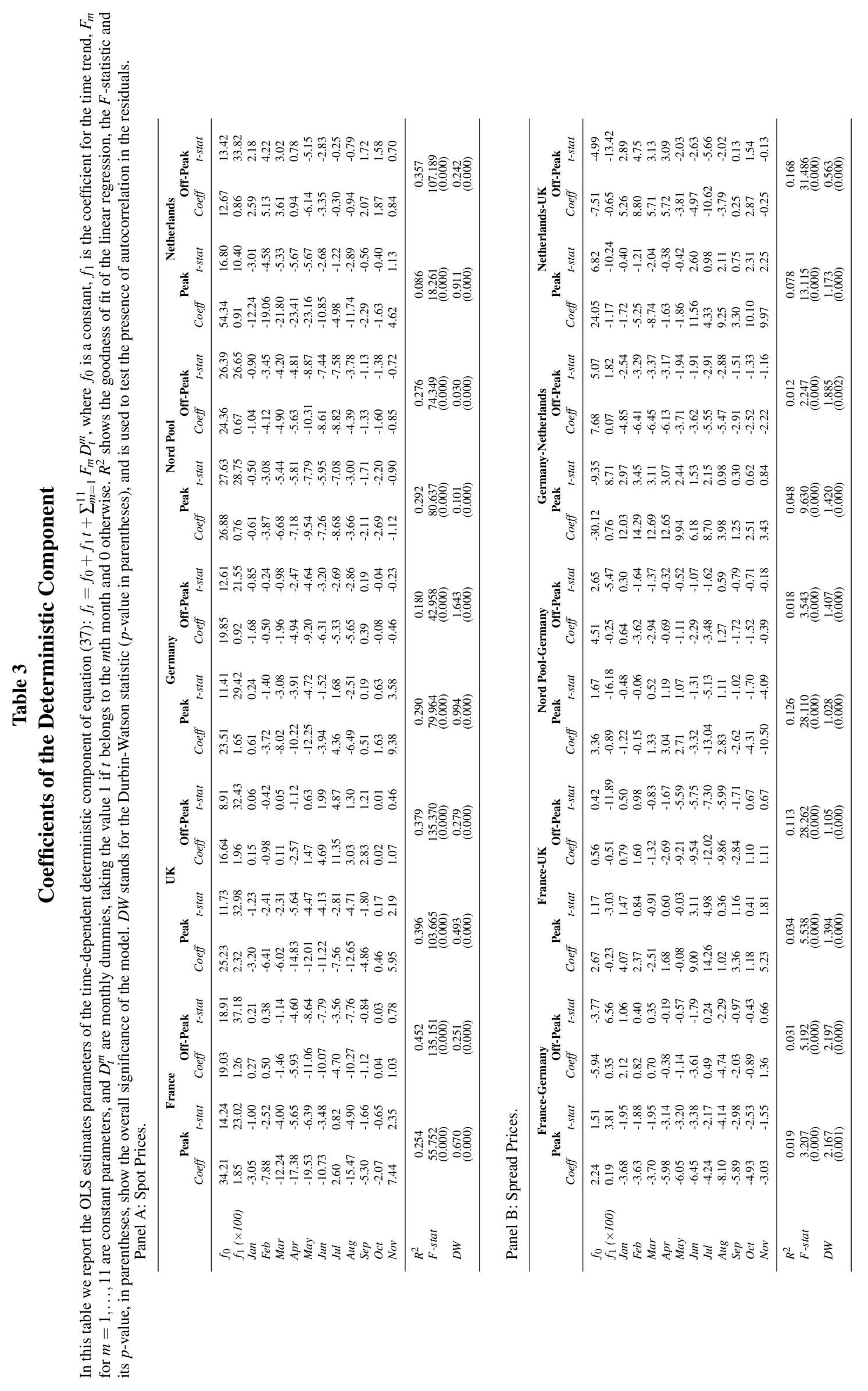




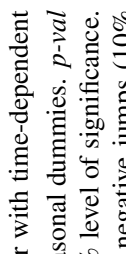

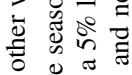

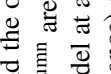

密

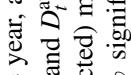

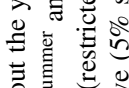

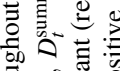

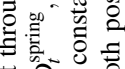

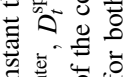

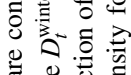

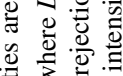

要

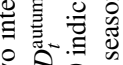

今a 


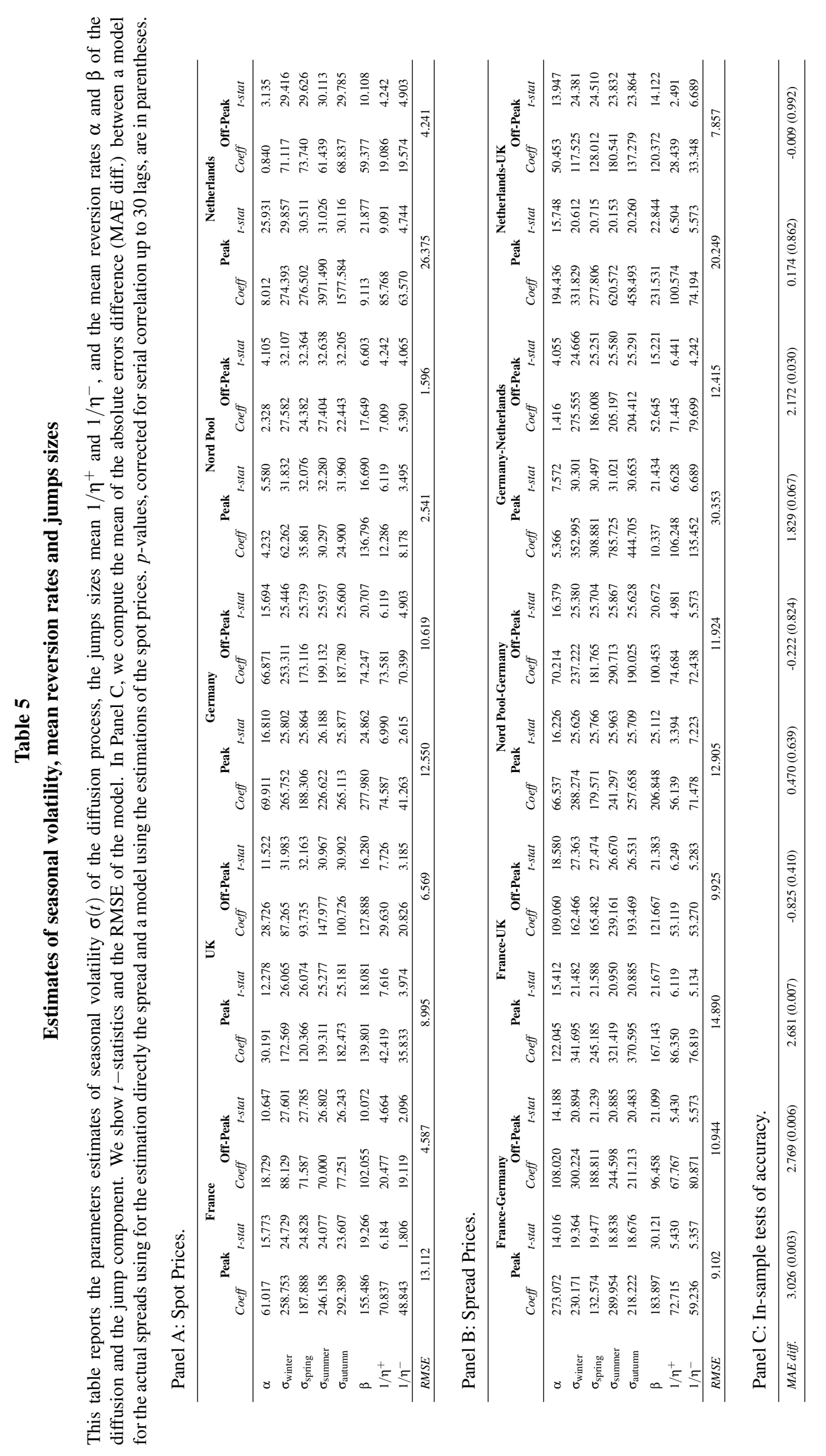




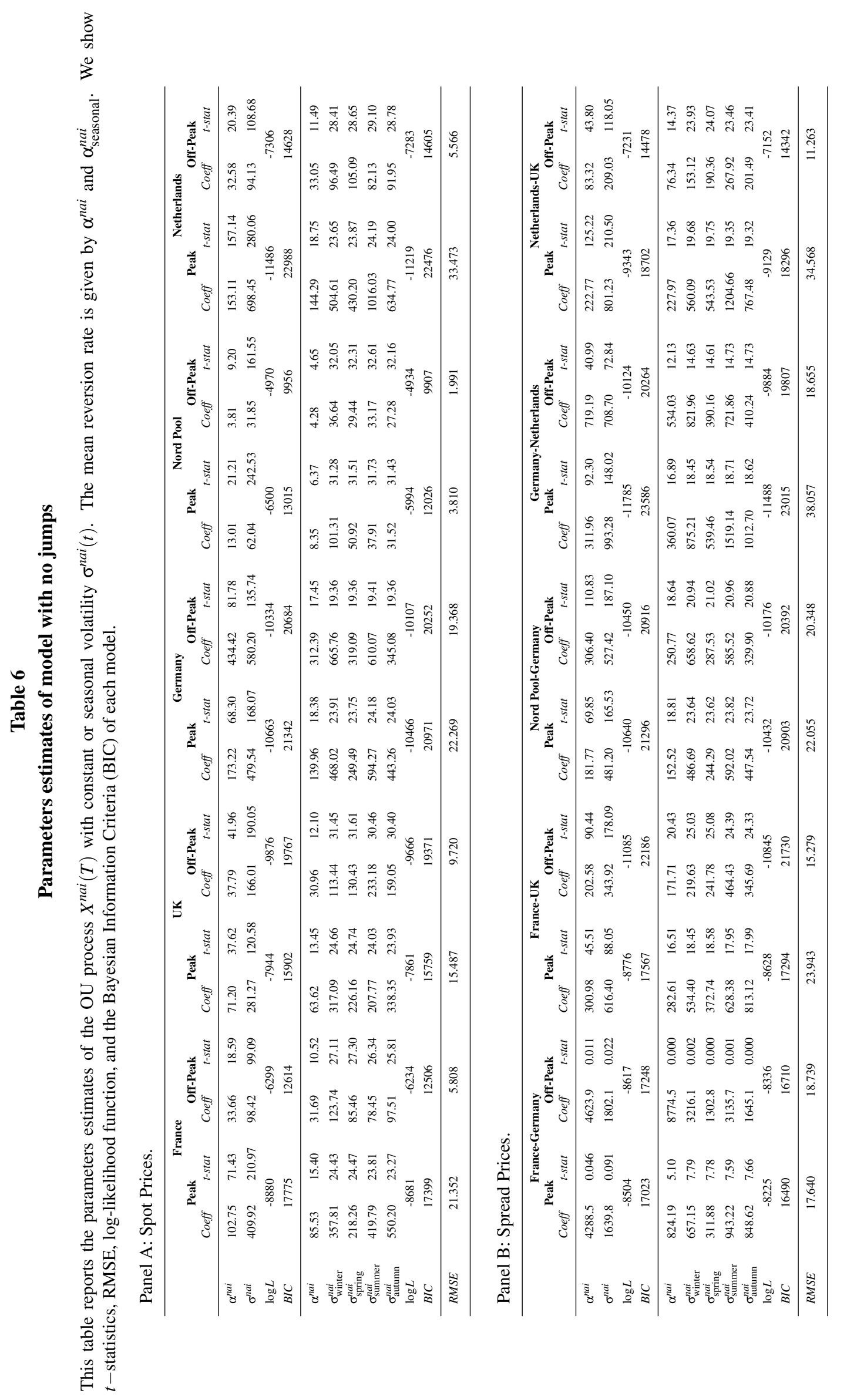


Table 7

Scenario 1: Value of one-year Interconnector lease

The model for the spread is (21), (22), and (23). The parameters of the seasonal component $f(T)$ are given in Table 3; the parameter estimates of the OU, $X(T)$, are in Panel B of Table 5; the parameters of the jump component, $Y(T)$, are at the bottom of Panel B in Table 5 and in Panel B of Table 4 . In columns 3 and 4 the intensity parameters, $\lambda_{\text {season }}^{ \pm}$of the positive and negative jumps are set to zero.
Seasonality, OU, and Jumps
OU and Jumps
Seasonality, OU, and Jumps
OU and Jumps
$S(T)=\quad f(T)+X(T)+Y(T)$
$f(T)+X(T)$
$f(T)+X(T)+Y(T)$
$f(T)+X(T)$

\begin{tabular}{|c|c|c|c|c|c|c|c|c|}
\hline \multirow[t]{2}{*}{$M$} & \multicolumn{4}{|c|}{ Peak France and Germany } & \multicolumn{4}{|c|}{ Off Peak France and Germany } \\
\hline & $\mathrm{Ger} \rightarrow \mathrm{Fr}$ & $\mathrm{Fr} \rightarrow \mathrm{Ger}$ & $\mathrm{Ger} \rightarrow \mathrm{Fr}$ & $\mathrm{Fr} \rightarrow \mathrm{Ger}$ & $\mathrm{Ger} \rightarrow \mathrm{Fr}$ & Fr $\rightarrow$ Ger & $\mathrm{Ger} \rightarrow \mathrm{Fr}$ & $\mathrm{Fr} \rightarrow \mathrm{Ger}$ \\
\hline 10 & 601 & 251 & 572 & 209 & 737 & 459 & 728 & 397 \\
\hline 20 & 1,136 & 467 & 1,002 & 337 & 1,697 & 1,023 & 1,605 & 805 \\
\hline 30 & 1,312 & 554 & 1,074 & 355 & 2,177 & 1,316 & 1,960 & 939 \\
\hline 40 & 1,398 & 605 & 1,081 & 357 & 2,416 & 1,488 & 2,077 & 975 \\
\hline 50 & 1,457 & 641 & 1,082 & 357 & 2,550 & 1,604 & 2,110 & 984 \\
\hline \multirow[t]{3}{*}{$\infty$} & 1,681 & 761 & 1,082 & 357 & 2,949 & 2,095 & 2,120 & 985 \\
\hline & \multicolumn{4}{|c|}{ Peak France and UK } & \multicolumn{4}{|c|}{ Off Peak France and UK } \\
\hline & $\mathrm{UK} \rightarrow \mathrm{Fr}$ & $\mathrm{Fr} \rightarrow \mathrm{UK}$ & $\mathrm{UK} \rightarrow \mathrm{Fr}$ & $\mathrm{Fr} \rightarrow \mathrm{UK}$ & $\mathrm{UK} \rightarrow \mathrm{Fr}$ & $\mathrm{Fr} \rightarrow \mathrm{UK}$ & $\mathrm{UK} \rightarrow \mathrm{Fr}$ & $\mathrm{Fr} \rightarrow \mathrm{UK}$ \\
\hline 10 & 616 & 661 & 580 & 662 & 89 & 1,333 & 41 & 1,382 \\
\hline 20 & 1,472 & 1,568 & 1,339 & 1,540 & 187 & 3,354 & 62 & 3,461 \\
\hline 30 & 1,960 & 2,058 & 1,717 & 1,975 & 243 & 4,472 & 64 & 4,565 \\
\hline 40 & 2,229 & 2,304 & 1,880 & 2,159 & 282 & 4,969 & 64 & 5,004 \\
\hline 50 & 2,382 & 2,430 & 1,940 & 2,2256 & 310 & 5,174 & 64 & 5,143 \\
\hline \multirow[t]{3}{*}{$\infty$} & 2,850 & 2,725 & 1,967 & 2,255 & 401 & 5,441 & 64 & 5,189 \\
\hline & \multicolumn{4}{|c|}{ Peak Nord Pool and Germany } & \multicolumn{4}{|c|}{ Off Peak Nord Pool and Germany } \\
\hline & $\mathrm{Ger} \rightarrow \mathrm{NP}$ & $\mathrm{NP} \rightarrow \mathrm{Ger}$ & $\mathrm{Ger} \rightarrow \mathrm{NP}$ & $\mathrm{NP} \rightarrow \mathrm{Ger}$ & $\mathrm{Ger} \rightarrow \mathrm{NP}$ & $\mathrm{NP} \rightarrow \mathrm{Ger}$ & Ger $\rightarrow$ NP & $\mathrm{NP} \rightarrow \mathrm{Ger}$ \\
\hline 10 & 66 & 1,512 & 61 & 1,508 & 432 & 829 & 403 & 815 \\
\hline 20 & 135 & 4,226 & 120 & 4,199 & 972 & 1,997 & 864 & 1,915 \\
\hline 30 & 165 & 6,391 & 140 & 6,313 & 1,246 & 2,651 & 1,052 & 2,465 \\
\hline 40 & 178 & 7,935 & 146 & 7,779 & 1,392 & 2,993 & 1,121 & 2,697 \\
\hline 50 & 186 & 8,920 & 147 & 8,671 & 1,478 & 3,177 & 1,143 & 2,784 \\
\hline \multirow[t]{3}{*}{$\infty$} & 206 & 10,302 & 148 & 9,510 & 1,762 & 3,628 & 1,153 & 2,826 \\
\hline & \multicolumn{4}{|c|}{ Peak Germany and Netherlands } & \multicolumn{4}{|c|}{ Off Peak Germany and Netherlands } \\
\hline & $\mathrm{Ne} \rightarrow \mathrm{Ger}$ & $\mathrm{Ger} \rightarrow \mathrm{Ne}$ & $\mathrm{Ne} \rightarrow \mathrm{Ger}$ & $\mathrm{Ger} \rightarrow \mathrm{Ne}$ & $\mathrm{Ne} \rightarrow \mathrm{Ger}$ & $\mathrm{Ger} \rightarrow \mathrm{Ne}$ & $\mathrm{Ne} \rightarrow \mathrm{Ger}$ & $\mathrm{Ger} \rightarrow \mathrm{Ne}$ \\
\hline 10 & 816 & 848 & 860 & 788 & 881 & 752 & 858 & 771 \\
\hline 20 & 2,377 & 2,475 & 2,491 & 2,279 & 2,540 & 2,156 & 2,465 & 2,210 \\
\hline 30 & 3,842 & 4,011 & 4,006 & 3,659 & 4,062 & 3,432 & 3,932 & 3,515 \\
\hline 40 & 5,215 & 5,459 & 5,407 & 4,932 & 5,455 & 4,585 & 5,265 & 4,692 \\
\hline 50 & 6,498 & 6,824 & 6,699 & 6,104 & 6,720 & 5,624 & 6,469 & 5,749 \\
\hline \multirow[t]{3}{*}{$\infty$} & 22,461 & 27,929 & 19,424 & 17,788 & 15,895 & 12,564 & 14,623 & 12,551 \\
\hline & \multicolumn{4}{|c|}{ Peak Netherlands and UK } & \multicolumn{4}{|c|}{ Off Peak Netherlands and UK } \\
\hline & $\mathrm{UK} \rightarrow \mathrm{Ne}$ & $\mathrm{Ne} \rightarrow \mathrm{UK}$ & $\mathrm{UK} \rightarrow \mathrm{Ne}$ & $\mathrm{Ne} \rightarrow \mathrm{UK}$ & $\mathrm{UK} \rightarrow \mathrm{Ne}$ & $\mathrm{Ne} \rightarrow \mathrm{UK}$ & $\mathrm{UK} \rightarrow \mathrm{Ne}$ & $\mathrm{Ne} \rightarrow \mathrm{UK}$ \\
\hline 10 & 390 & 971 & 347 & 993 & 18 & 1,586 & 14 & 1,582 \\
\hline 20 & 939 & 2,438 & 803 & 2,471 & 31 & 4,364 & 21 & 4,320 \\
\hline 30 & 1,283 & 3,313 & 1,054 & 3,321 & 37 & 6,351 & 22 & 6,214 \\
\hline 40 & 1,501 & 3,770 & 1,187 & 3,732 & 39 & 7,506 & 22 & 7,239 \\
\hline 50 & 1,641 & 3,996 & 1,254 & 3,909 & 41 & 8,074 & 22 & 7,676 \\
\hline$\infty$ & 2,112 & 4,359 & 1,308 & 4,033 & 44 & 8,606 & 22 & 7,892 \\
\hline
\end{tabular}


Table 8

\section{Scenario 1 (cont): Value of one-year Interconnector lease}

The model for the spread is (21), (22), and (23). The parameters of the seasonal component $f(T)$ are given in Table 3; the parameter estimates of the OU, $X(T)$, are in Panel B of Table 5; and we set all intensities $\lambda$ of Table 4 to zero. Although the estimation of the parameters is performed including the seasonal component $f(T)$ we value the one-year lease without including the seasonal component $f(T)$. Not including the predictable component $f(T)$ allows us to quantify how much of the value of the interconnector is derived from the deterministic seasonal level by comparing these results with those of Table 7 .

\begin{tabular}{|c|c|c|c|c|c|c|c|c|}
\hline$S(T)=$ & \multicolumn{2}{|c|}{$\begin{array}{c}\text { OU and Jumps } \\
X(T)+Y(T)\end{array}$} & \multicolumn{2}{|c|}{$\begin{array}{c}\mathrm{OU} \\
X(T) \\
\end{array}$} & \multicolumn{2}{|c|}{$\begin{array}{c}\text { OU and Jumps } \\
X(T)+Y(T)\end{array}$} & \multicolumn{2}{|c|}{$\begin{array}{c}\mathrm{OU} \\
X(T) \\
\end{array}$} \\
\hline$M$ & \multicolumn{4}{|c|}{ Peak France and Germany } & \multicolumn{4}{|c|}{ Off Peak France and Germany } \\
\hline 10 & 397 & 386 & 352 & 352 & 579 & 596 & 549 & 549 \\
\hline 20 & 735 & 703 & 579 & 579 & 1,294 & 1,347 & 1,157 & 1,157 \\
\hline 30 & 862 & 811 & 611 & 611 & 1,642 & 1,729 & 1,376 & 1,376 \\
\hline 50 & 987 & 909 & 614 & 614 & 1,932 & 2,076 & 1,458 & 1,458 \\
\hline \multirow[t]{3}{*}{$\infty$} & 1,194 & 1,039 & 614 & 614 & 2,290 & 2,613 & 1,463 & 1,463 \\
\hline & \multicolumn{4}{|c|}{ Peak France and UK } & \multicolumn{4}{|c|}{ Off Peak France and UK } \\
\hline & $\mathrm{UK} \rightarrow \mathrm{Fr}$ & $\mathrm{Fr} \rightarrow \mathrm{UK}$ & $\mathrm{UK} \rightarrow \mathrm{Fr}$ & $\mathrm{Fr} \rightarrow \mathrm{UK}$ & $\mathrm{UK} \rightarrow \mathrm{Fr}$ & $\mathrm{Fr} \rightarrow \mathrm{UK}$ & $\mathrm{UK} \rightarrow \mathrm{Fr}$ & $\mathrm{Fr} \rightarrow \mathrm{UK}$ \\
\hline 10 & 649 & 615 & 614 & 614 & 522 & 495 & 481 & 481 \\
\hline 20 & 1,542 & 1,443 & 1,411 & 1,411 & 1,063 & 993 & 916 & 916 \\
\hline \multirow[t]{3}{*}{$\infty$} & 2,921 & 2,506 & 2,041 & 2,041 & 1,569 & 1,408 & 1,048 & 1,048 \\
\hline & \multicolumn{4}{|c|}{ Peak Nord Pool and Germany } & \multicolumn{4}{|c|}{ Off Peak Nord Pool and Germany } \\
\hline & Ger $\rightarrow$ NP & $\mathrm{NP} \rightarrow \mathrm{Ger}$ & $\mathrm{Ger} \rightarrow \mathrm{NP}$ & $\mathrm{NP} \rightarrow \mathrm{Ger}$ & $\mathrm{Ger} \rightarrow \mathrm{NP}$ & $\mathrm{NP} \rightarrow \mathrm{Ger}$ & $\mathrm{Ger} \rightarrow \mathrm{NP}$ & $\mathrm{NP} \rightarrow \mathrm{Ger}$ \\
\hline 10 & 594 & 663 & 618 & 618 & 608 & 625 & 593 & 593 \\
\hline 20 & 1,379 & 1,572 & 1,429 & 1,429 & 1,405 & 1,454 & 1,328 & 1,328 \\
\hline 30 & 1,777 & 2,071 & 1,832 & 1,832 & 1,819 & 1,893 & 1,657 & 1,657 \\
\hline 40 & 1,957 & 2,330 & 2,005 & 2,005 & 2,030 & 2,124 & 1,785 & 1,785 \\
\hline 50 & 2,034 & 2,465 & 2,071 & 2,071 & 2,147 & 2,255 & 1,829 & 1,829 \\
\hline \multirow[t]{3}{*}{$\infty$} & 2,111 & 2,765 & 2,102 & 2,102 & 2,478 & 2,633 & 1,849 & 1,849 \\
\hline & \multicolumn{4}{|c|}{ Peak Germany and Netherlands } & \multicolumn{4}{|c|}{ Off Peak Germany and Netherlands } \\
\hline & $\mathrm{Ne} \rightarrow \mathrm{Ger}$ & $\mathrm{Ger} \rightarrow \mathrm{Ne}$ & $\mathrm{Ne} \rightarrow \mathrm{Ger}$ & $\mathrm{Ger} \rightarrow \mathrm{Ne}$ & $\mathrm{Ne} \rightarrow \mathrm{Ger}$ & $\mathrm{Ger} \rightarrow \mathrm{Ne}$ & $\mathrm{Ne} \rightarrow \mathrm{Ger}$ & $\mathrm{Ger} \rightarrow \mathrm{Ne}$ \\
\hline 10 & 641 & 609 & 610 & 610 & 473 & 578 & 507 & 507 \\
\hline 20 & 1,520 & 1,427 & 1,403 & 1,403 & 944 & 1,219 & 1,006 & 1,006 \\
\hline 30 & 2,024 & 1,875 & 1,809 & 1,809 & 1,088 & 1,475 & 1,151 & 1,151 \\
\hline 40 & 2,316 & 2,119 & 2,006 & 2,006 & 1,128 & 1,583 & 1,185 & 1,185 \\
\hline 50 & 2,495 & 2,255 & 2,101 & 2,101 & 1,141 & 1,637 & 1,191 & 1,191 \\
\hline$\infty$ & 3,042 & 2,528 & 2,178 & 2,178 & 1,153 & 1,727 & 1,193 & 1,193 \\
\hline
\end{tabular}


Table 9

Scenario 2: The underlying spread dynamics are modeled as a combination of seasonal and Gaussian component (no jumps)

Here we assume that the parameters of the spread dynamics are estimated assuming model containing a seasonal component $f(T)$ and an OU component $X^{\text {nai }}(T)$ given by (28). The parameter estimates for the seasonal component are in Table 3 and the parameter estimates for the OU are in Table 6. Note that we do not model jumps in the spread and that the estimation of the parameters is based on the model $f(T)+X^{n a i}(T)$.

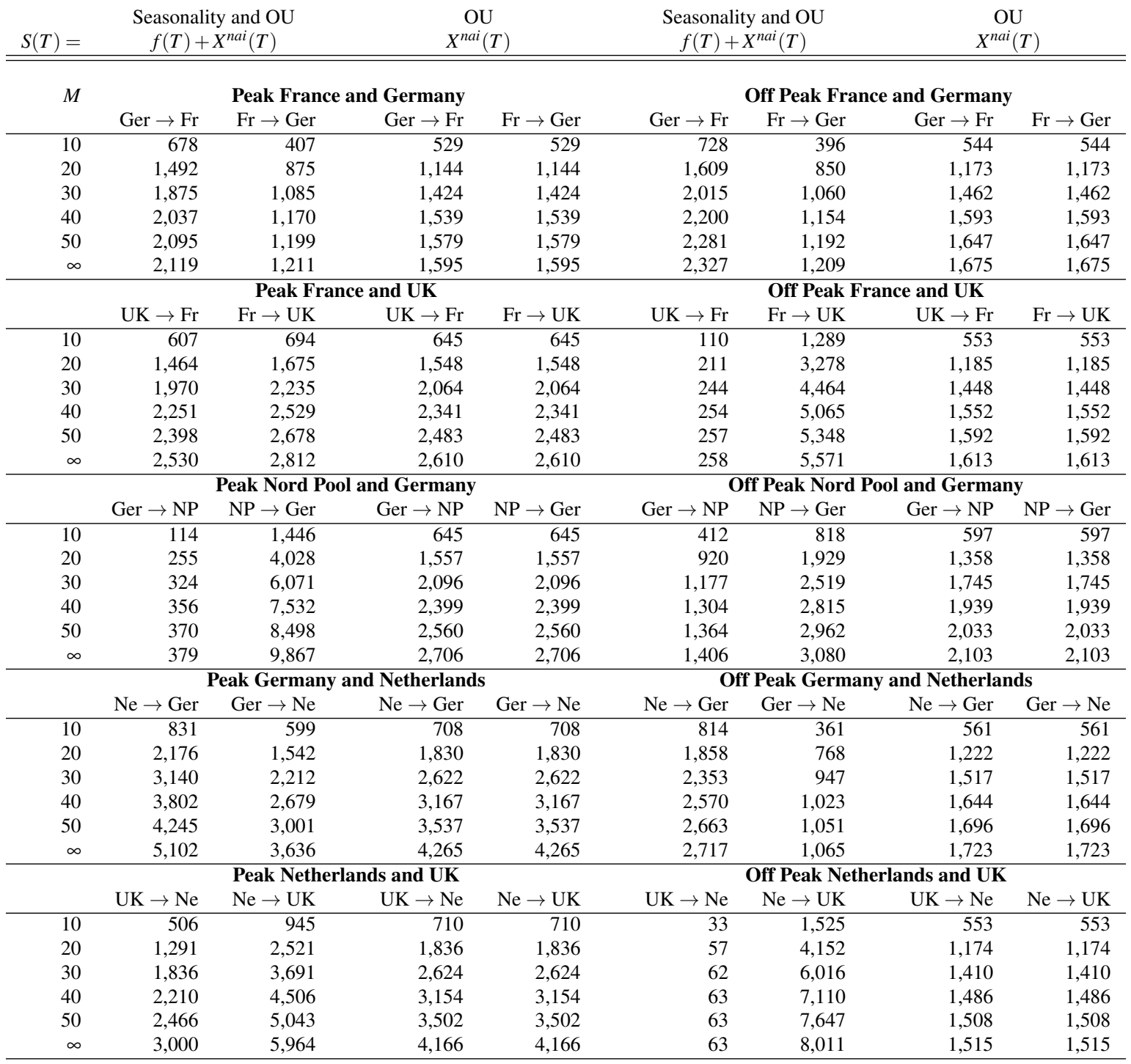



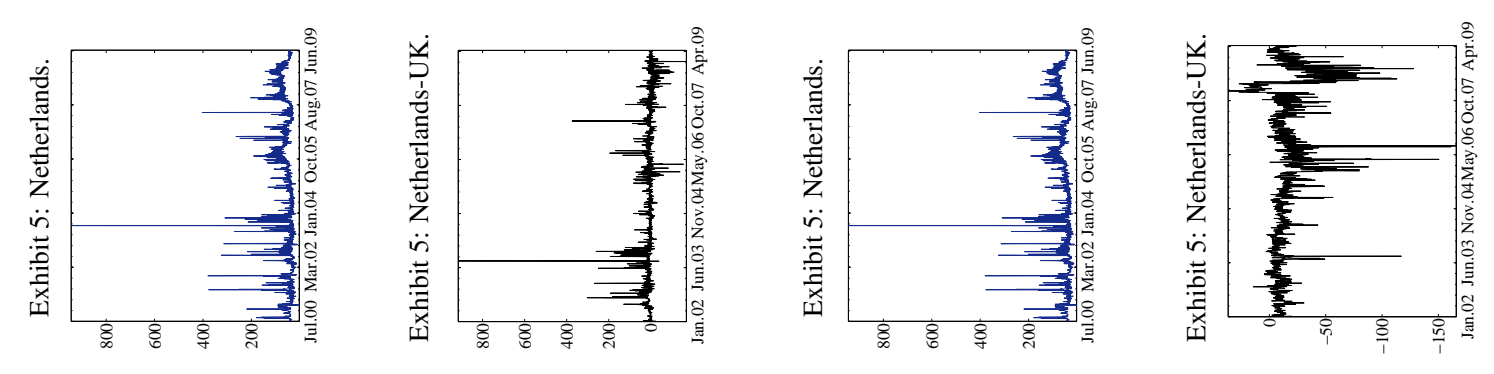

$\overparen{0}$
$\Xi$
$\frac{1}{0}$
$\frac{\pi}{2}$
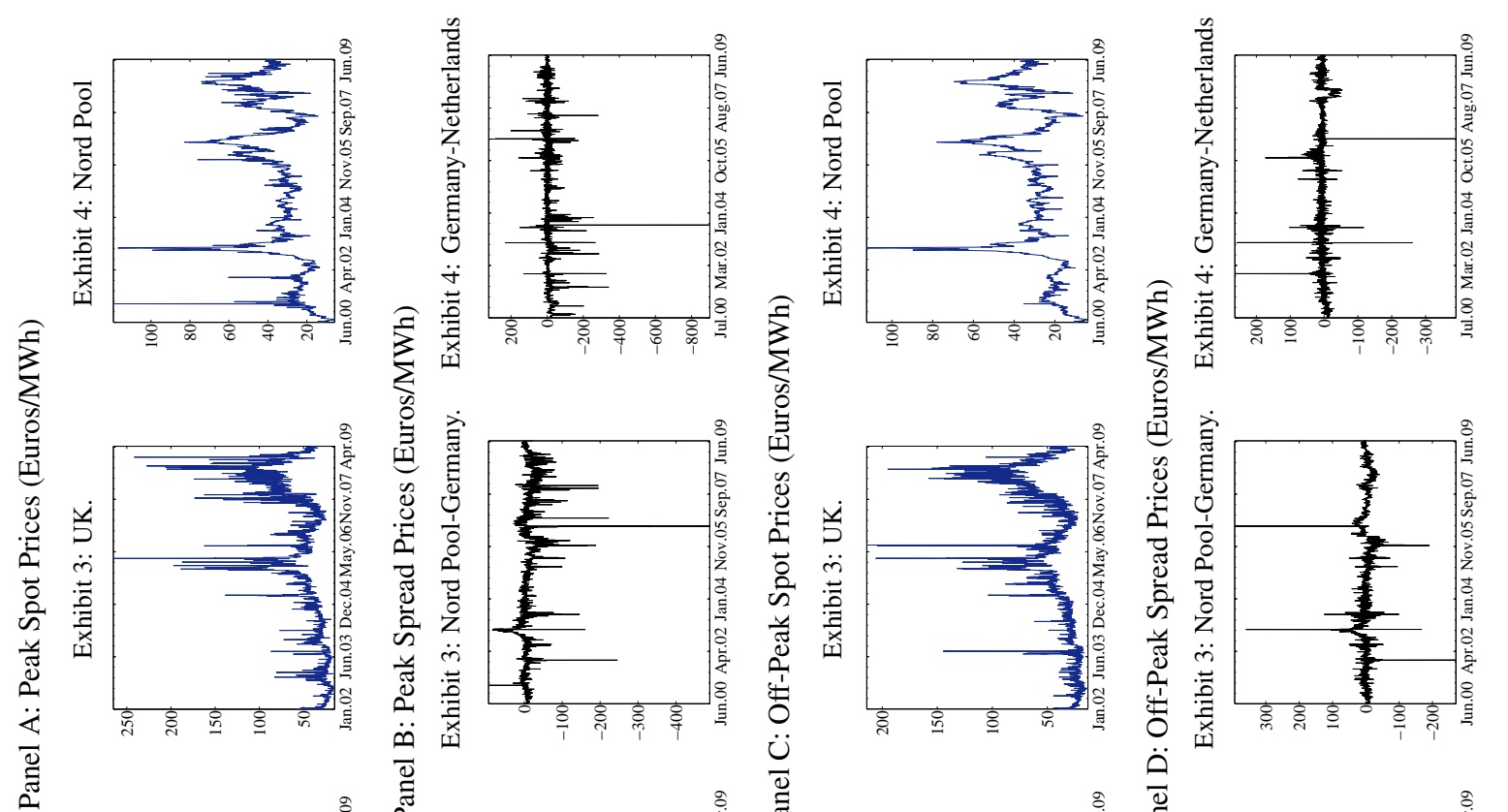

త్ర్ల
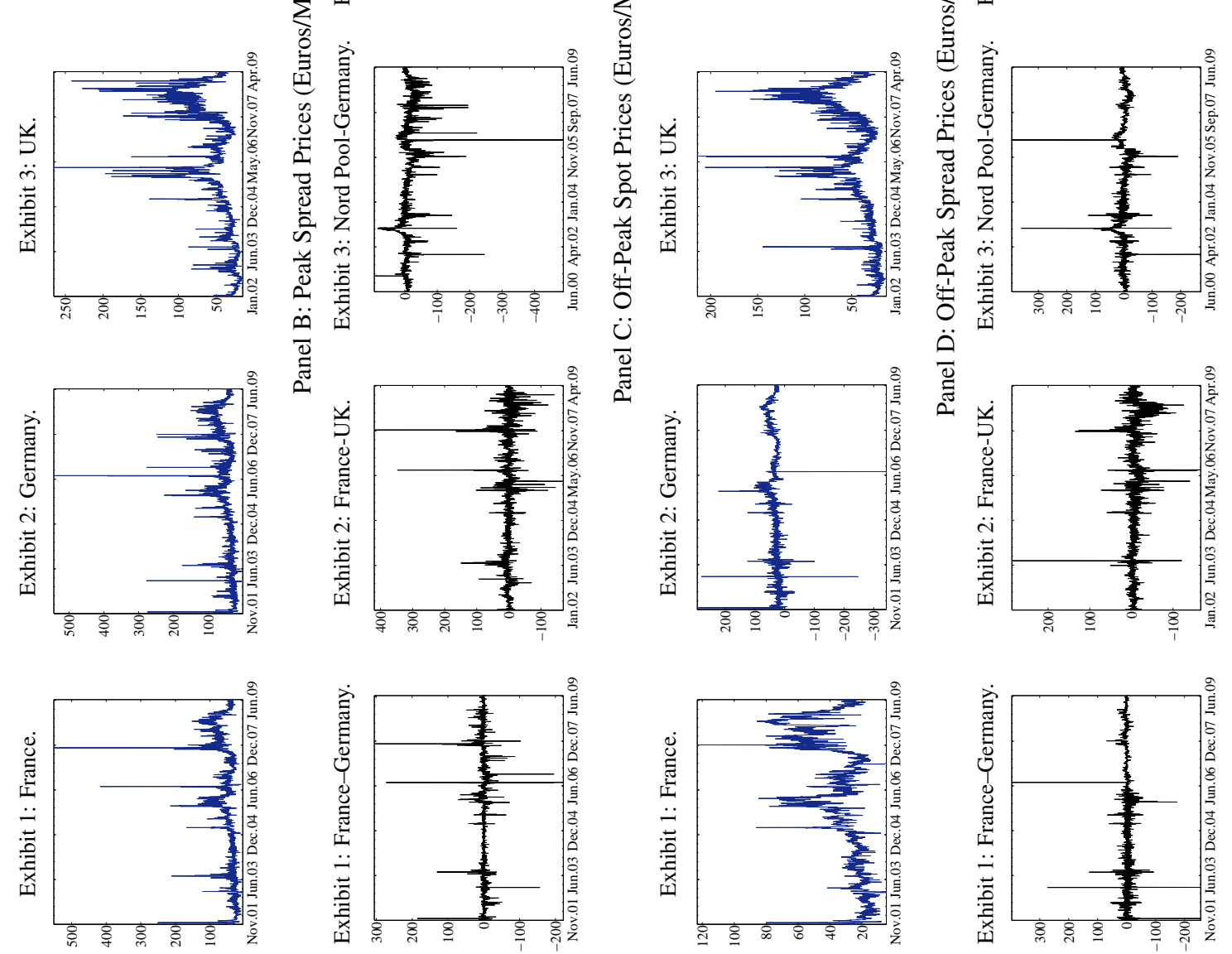

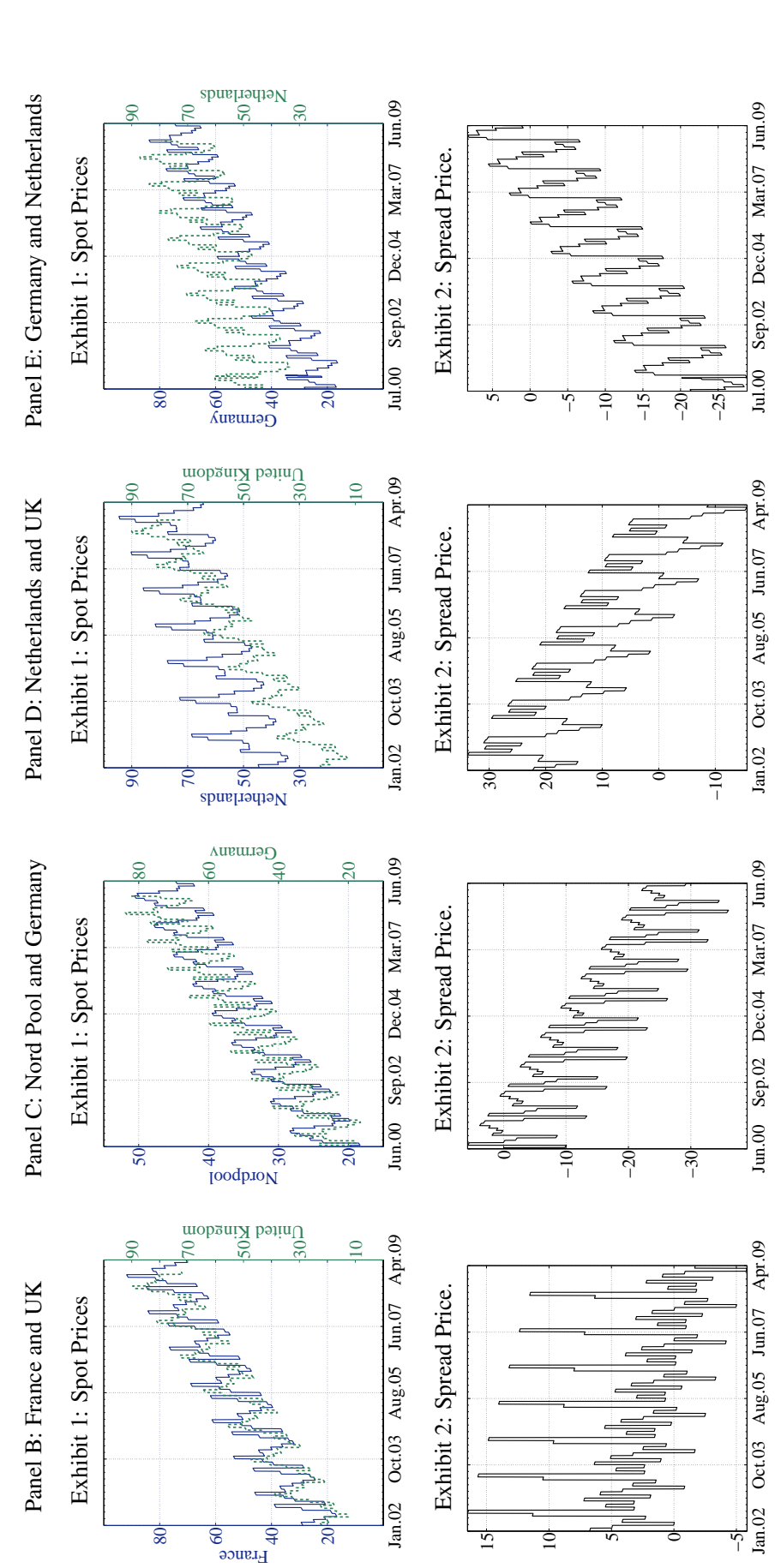

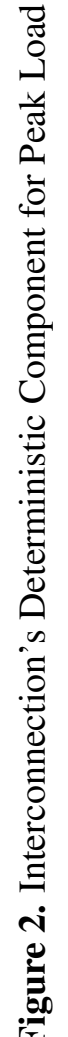

을

范

ह

ํํㅇ

동

ตัต

䒿

ㅎ․․․

:

ํㅛㅇ

ฮ

\%

:

文齐

के

훙

可 뭉

을

율

है

.

을 피

男.

글

을

o

no

응

金起

的气

i 0 نे

北市

$<$ 过

웅

运

ت
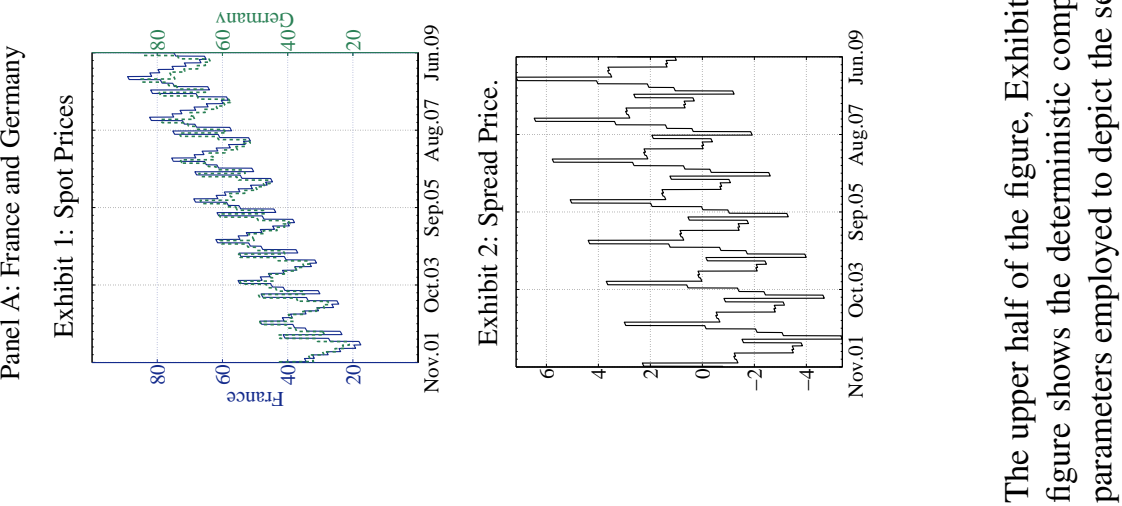

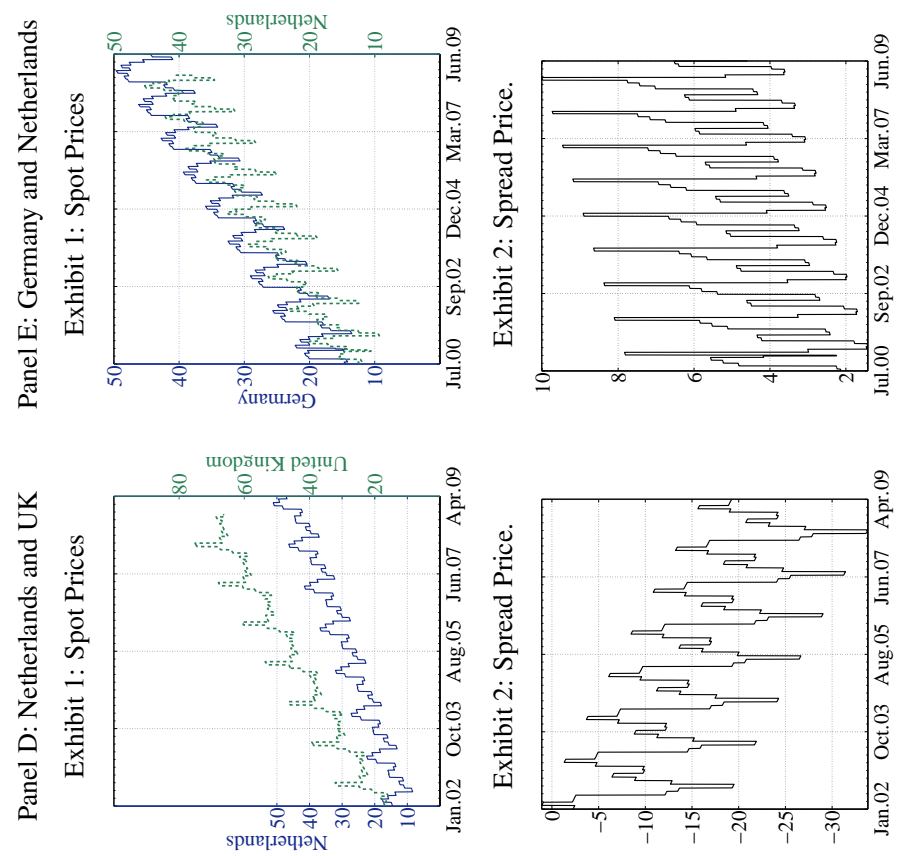

을 等
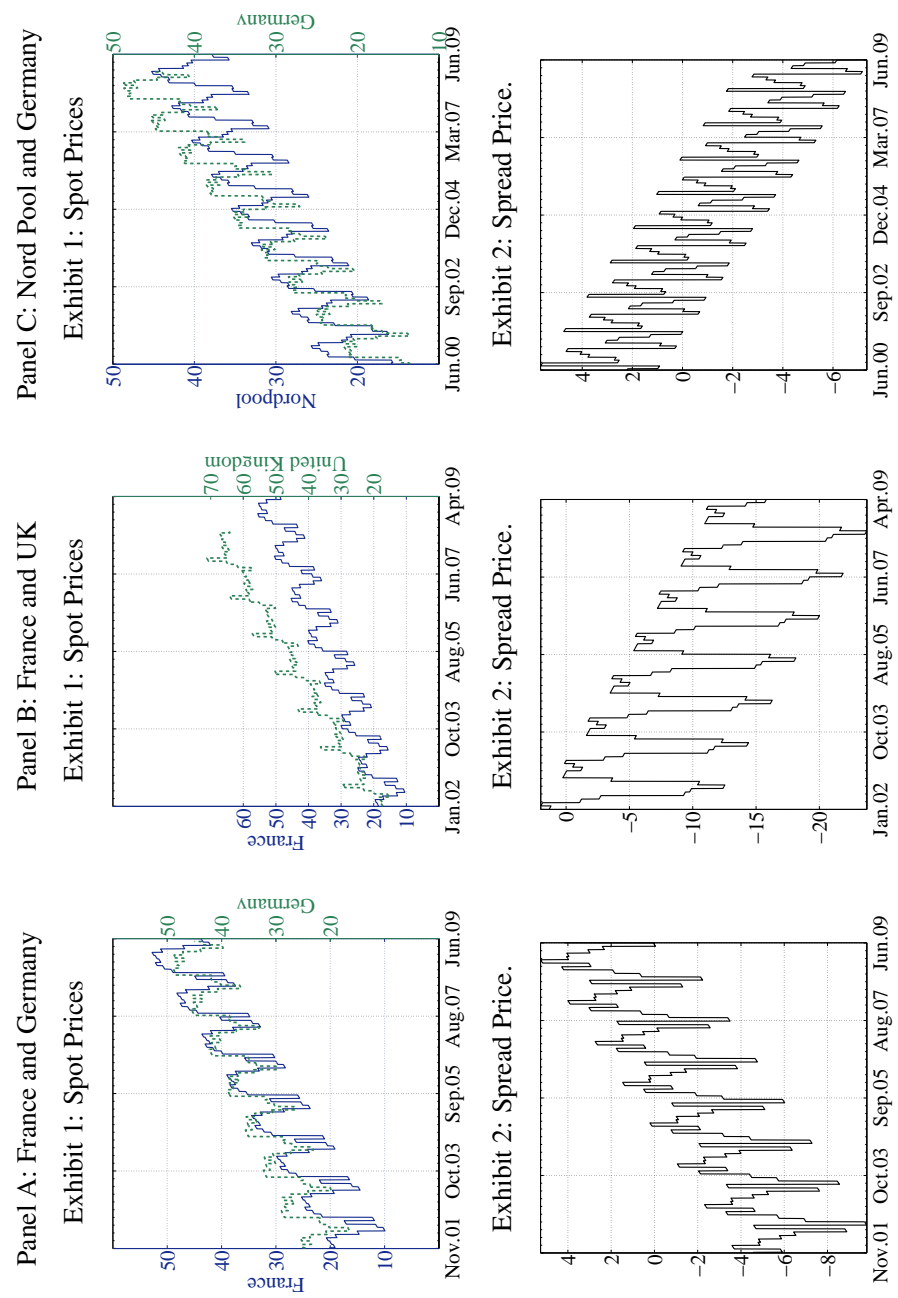
Panel A: Interconnection between France and Germany

Exhibit 1: Peak Price France (Euros/MWh).

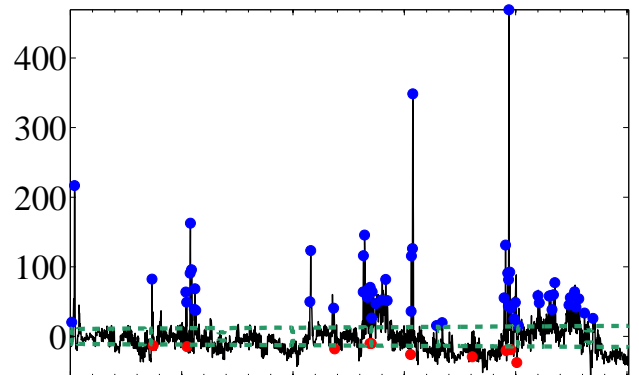

Nov.01 Jun.03 Dec.04 Jun.06 Dec.07 Jun.09

Exhibit 3: Peak Price Germany (Euros/MWh).

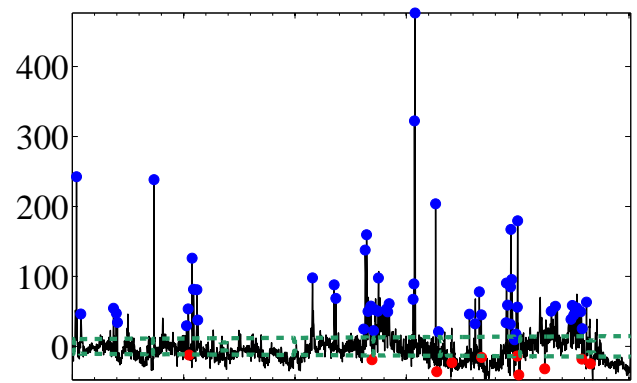

Nov.01 Jun.03 Dec.04 Jun.06 Dec.07 Jun.09

Exhibit 5: Peak Spread France-Germany (Euros/MWh).

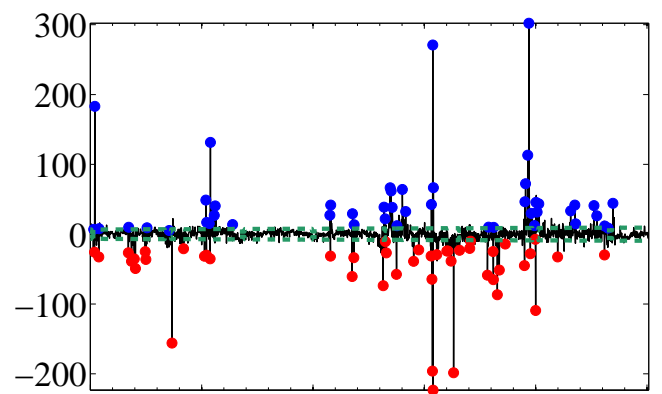

Nov.01 Jun.03 Dec.04 Jun.06 Dec.07 Jun.09
Exhibit 2: Off-Peak Price France (Euros/MWh).

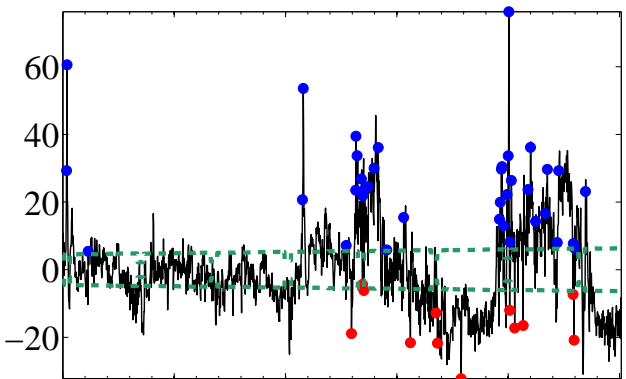

Nov.01 Jun.03 Dec.04 Jun.06 Dec.07 Jun.09

Exhibit 4: Off-Peak Price Germany (Euros/MWh).

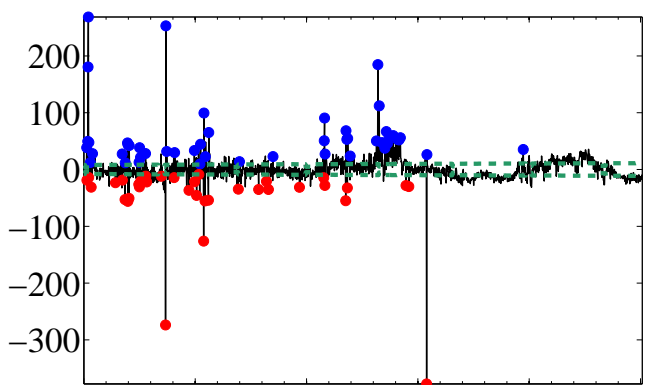

Nov.01 Jun.03 Dec.04 Jun.06 Dec.07 Jun.09

Exhibit 6: Off-Peak Spread France-Germany (Euros/MWh).

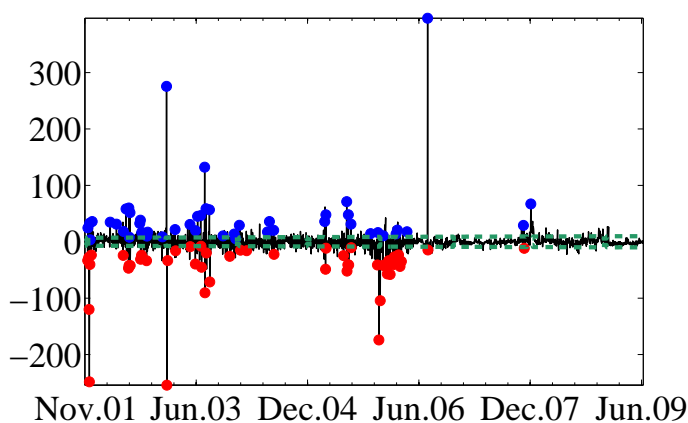

Figure 3. Detecting Jumps from the Jump Diffusion Process

Spot price series $S^{i}$ for both markets in the two possible load regimes: peak and off-Peak (Exhibits 1, 2, 3 and 4); and their spread series $S^{i, j}$ (Exhibits 5 and 6). The green dashed line represents the $95 \%$ confidence intervals for the deterministic component for each series. The red circles mark the presence of a negative jump, while the blue circles show the position of a positive jump. 
Panel B: Interconnection between France and United Kingdom

Exhibit 1: Peak Price France (Euros/MWh).

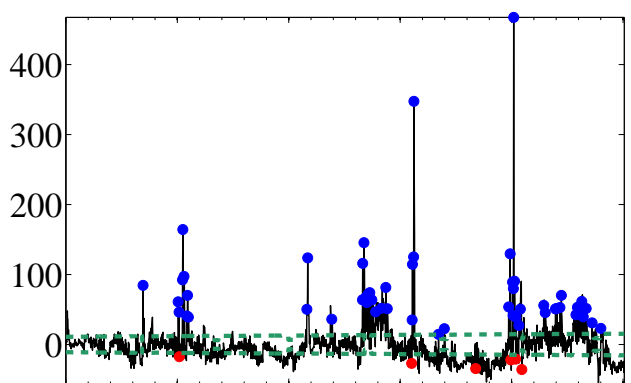

Jan.02 Jun.03 Dec.04 May.06 Nov.07 Apr.09

Exhibit 3: Peak Price United Kingdom (Euros/MWh).

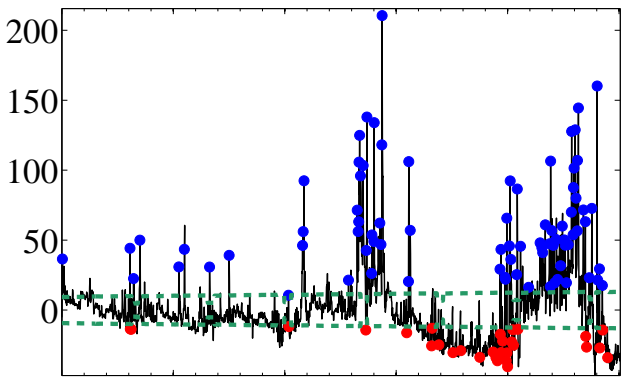

Jan.02 Jun.03 Dec.04 May.06 Nov.07 Apr.09

Exhibit 5: Peak Spread France-United Kingdom (Euros/MWh).

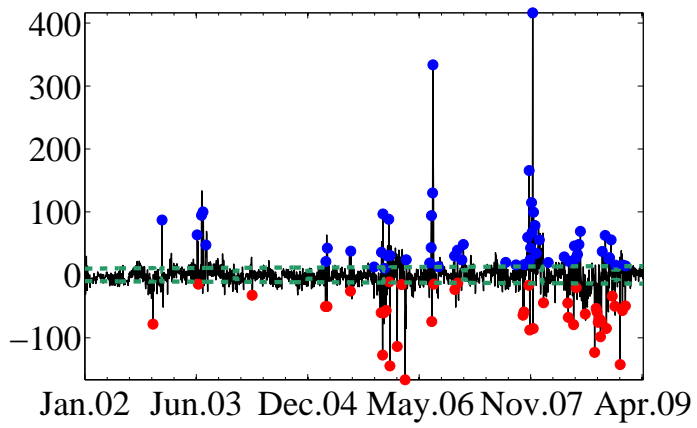

Exhibit 2: Off-Peak Price France (Euros/MWh).

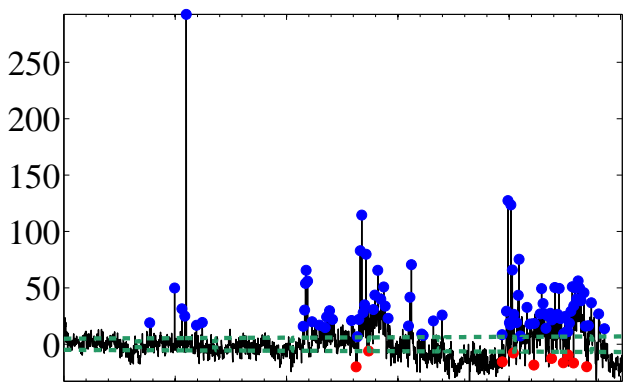

Jan.02 Jun.03 Dec.04 May.06 Nov.07 Apr.09

Exhibit 4: Off-Peak Price United Kingdom (Euros/MWh).

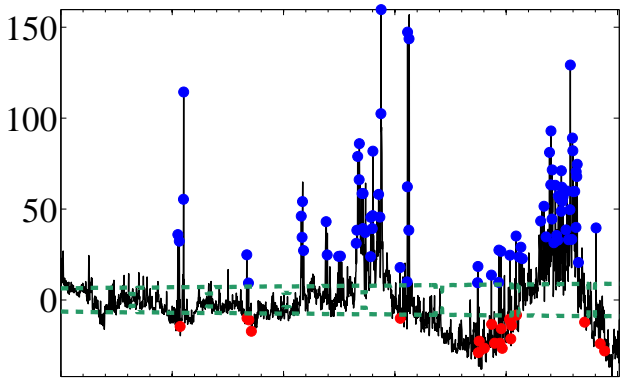

Jan.02 Jun.03 Dec.04 May.06 Nov.07 Apr.09

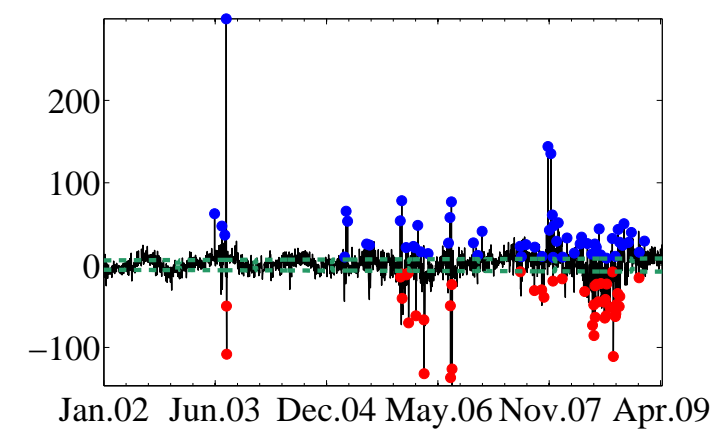

Figure 3 (continued). Detecting Jumps from the Jump Diffusion Process

Spot price series $S^{i}$ for both markets in the two possible load regimes: peak and off-Peak (Exhibits 1, 2, 3 and 4); and their spread series $S^{i, j}$ (Exhibits 5 and 6). The green dashed line represents the $95 \%$ confidence intervals for the deterministic component for each series. The red circles represent negative jumps, and the blue circles represent positive jumps. 
Panel C: Interconnection between Nord Pool and Germany

Exhibit 1: Peak Price Nord Pool (Euros/MWh).

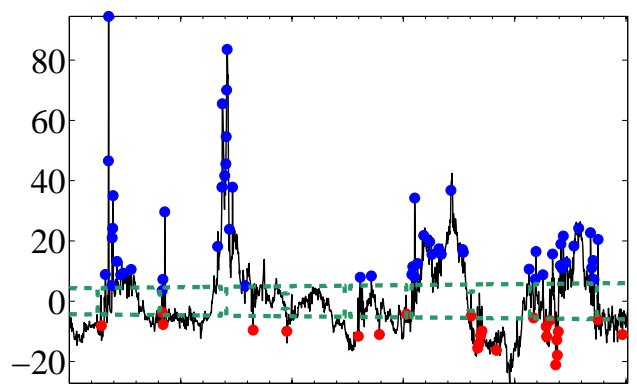

Jun.00 Apr.02 Jan.04 Nov.05 Sep.07 Jun.09

Exhibit 3: Peak Price Germany (Euros/MWh).

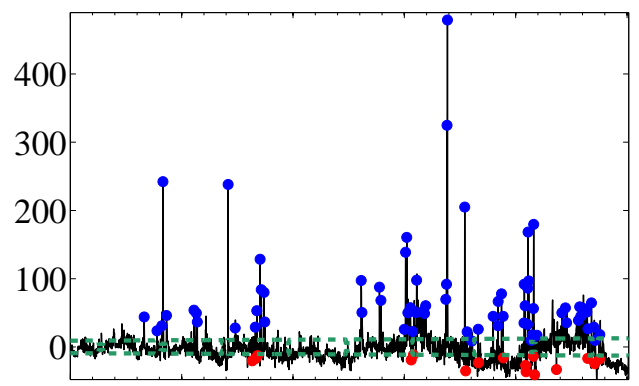

Jun.00 Apr.02 Jan.04 Nov.05 Sep.07 Jun.09

Exhibit 5: Peak Spread Nord Pool-Germany (Euros/MWh).

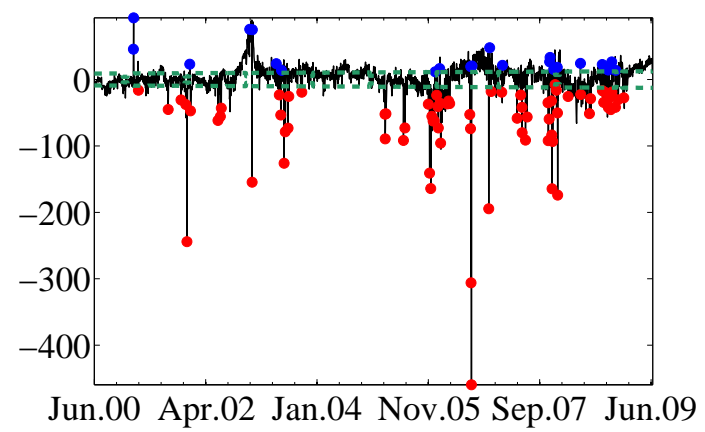

Exhibit 2: Off-Peak Price Nord Pool (Euros/MWh).

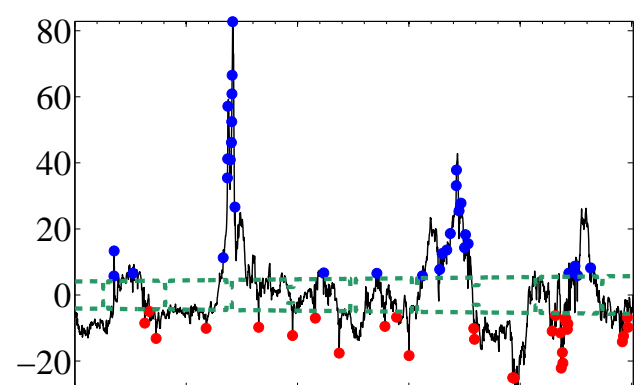

Jun.00 Apr.02 Jan.04 Nov.05 Sep.07 Jun.09

Exhibit 4: Off-Peak Price Germany (Euros/MWh).

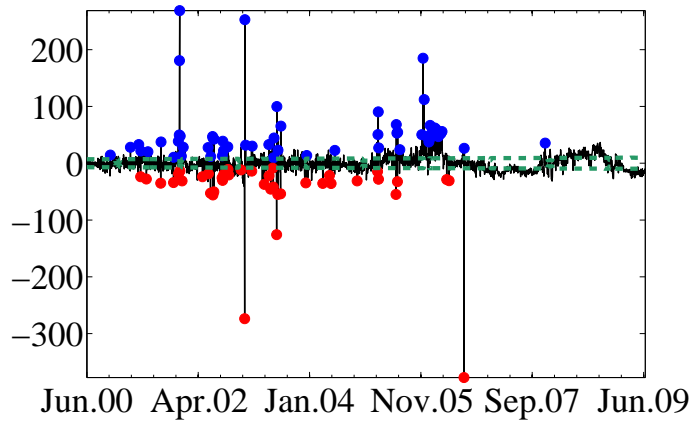

Exhibit 6: Off-Peak Spread Nord Pool-Germany (Euros/MWh).

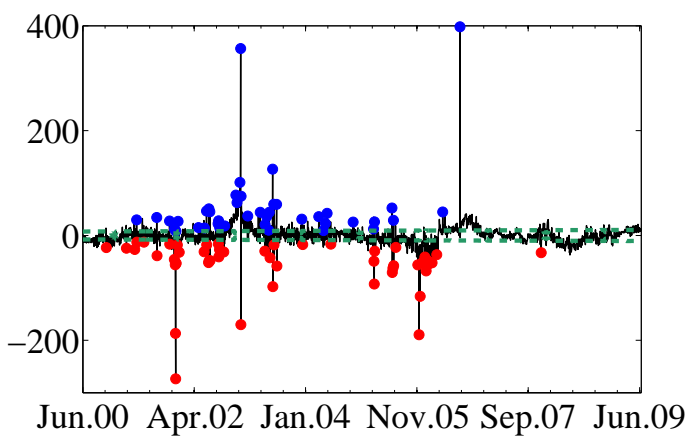

Figure 3 (continued). Detecting Jumps from the Jump Diffusion Process

Spot price series $S^{i}$ for both markets in the two possible load regimes: peak and off-Peak (Exhibits 1, 2, 3 and 4); and their spread series $S^{i, j}$ (Exhibits 5 and 6). The green dashed line represents the $95 \%$ confidence intervals for the deterministic component for each series. The red circles represent negative jumps, and the blue circles represent positive jumps. 
Panel D: Interconnection between Netherlands and United Kingdom

Exhibit 1: Peak Price Netherlands (Euros/MWh).

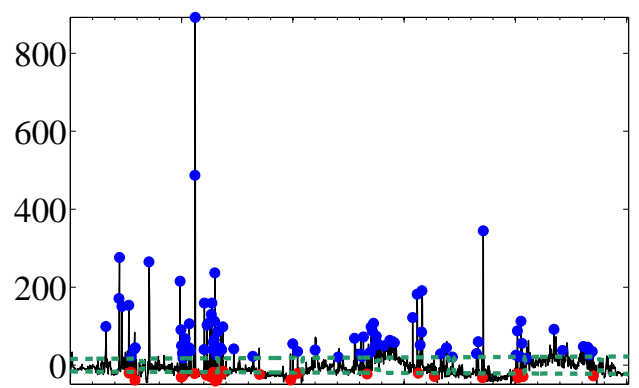

Jan.02 Jun.03 Nov.04 May.06 Oct.07 Apr.09

Exhibit 3: Peak Price United Kingdom (Euros/MWh).

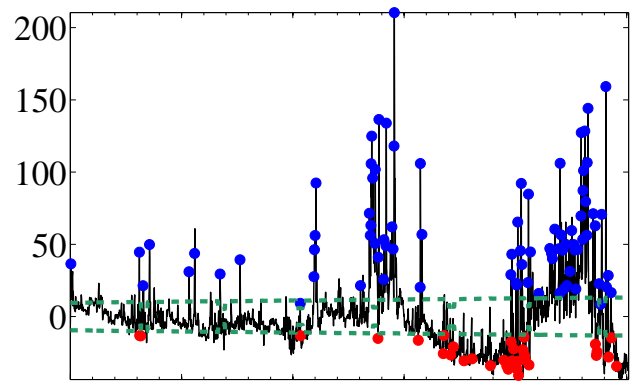

Jan.02 Jun.03 Nov.04 May.06 Oct.07 Apr.09

Exhibit 5: Peak Spread Netherlands-UK (Euros/MWh).

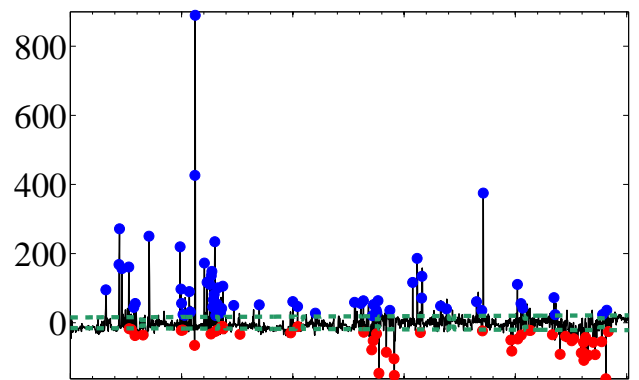

Jan.02 Jun.03 Nov.04 May.06 Oct.07 Apr.09
Exhibit 2: Off-Peak Price Netherlands (Euros/MWh).

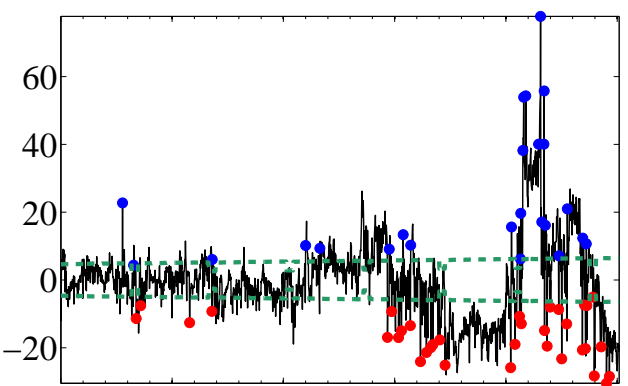

Jan.02 Jun.03 Nov.04 May.06 Oct.07 Apr.09

Exhibit 4: Off-Peak Price United Kingdom (Euros/MWh).

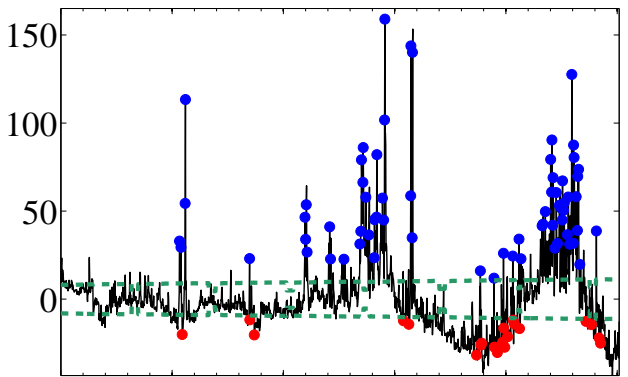

Jan.02 Jun.03 Nov.04 May.06 Oct.07 Apr.09

Exhibit 6: Off-Peak Spread Netherlands-UK (Euros/MWh).

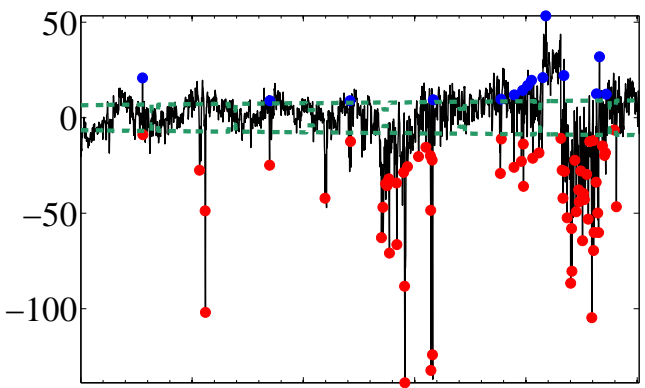

Jan.02 Jun.03 Nov.04 May.06 Oct.07 Apr.09

Figure 3 (continued). Detecting Jumps from the Jump Diffusion Process

Spot price series $S^{i}$ for both markets in the two possible load regimes: peak and off-Peak (Exhibits 1, 2, 3 and 4); and their spread series $S^{i, j}$ (Exhibits 5 and 6). The green dashed line represents the $95 \%$ confidence intervals for the deterministic component for each series. The red circles represent negative jumps, and the blue circles represent positive jumps. 
Panel E: Interconnection between Germany and Netherlands.

Exhibit 1: Peak Price Germany (Euros/MWh).

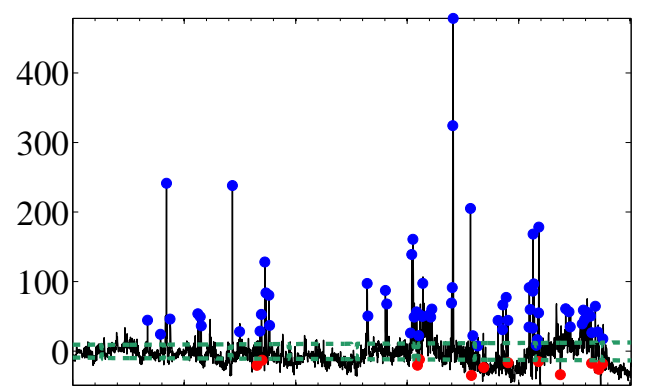

Jul.00 Mar.02 Jan.04 Oct.05 Aug.07 Jun.09

Exhibit 3: Peak Price Netherlands (Euros/MWh).

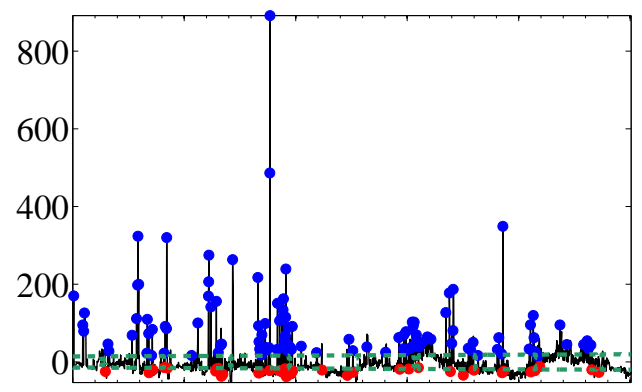

Jul.00 Mar.02 Jan.04 Oct.05 Aug.07 Jun.09

Exhibit 5: Peak Spread Germany-Netherlands (Euros/MWh).

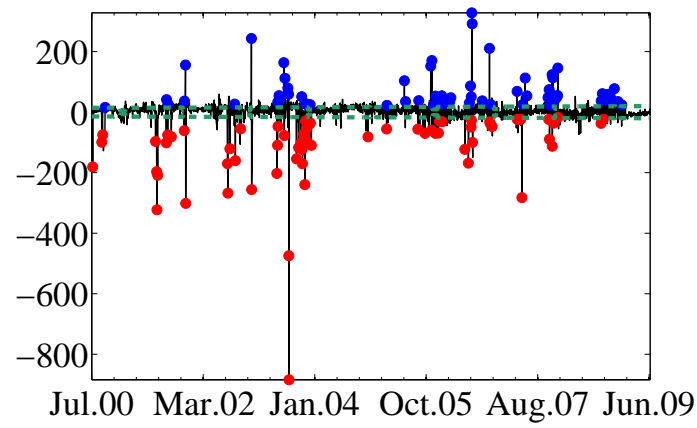

Exhibit 2: Off-Peak Price Germany (Euros/MWh).
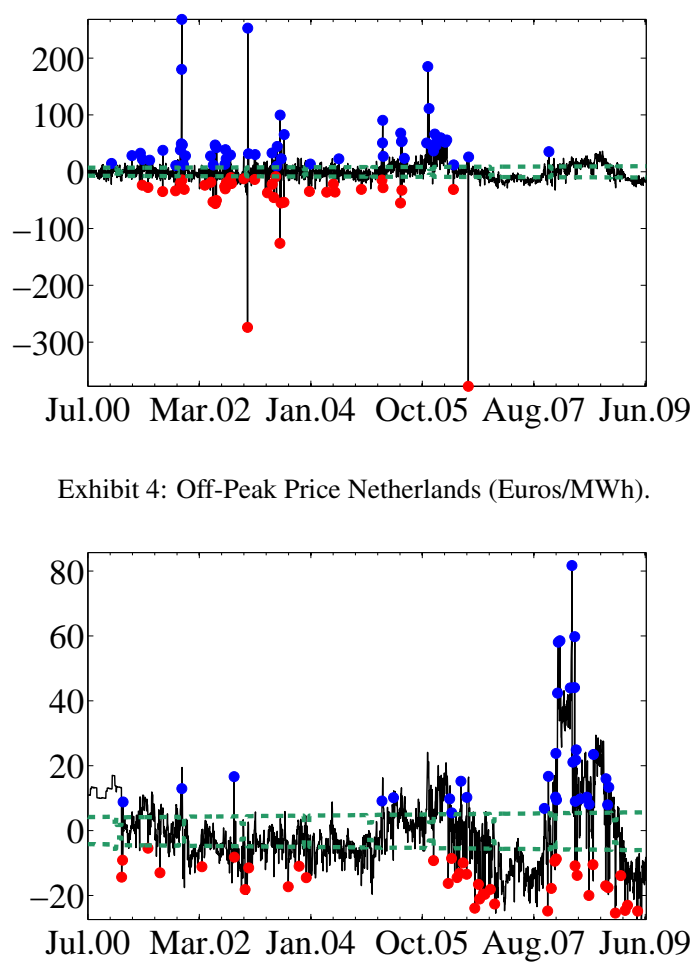

Exhibit 6: Off-Peak Spread Germany-Netherlands (Euros/MWh).

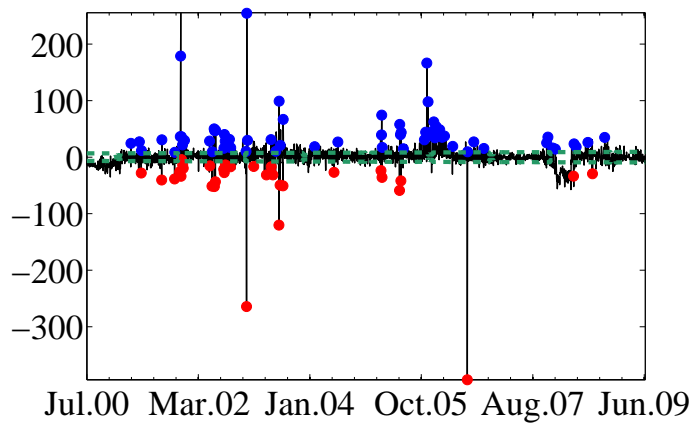

Figure 3 (continued). Detecting Jumps from the Jump Diffusion Process.

Spot price series $S^{i}$ for both markets in the two possible load regimes: peak and off-Peak (Exhibits 1, 2, 3 and 4); and their spread series $S^{i, j}$ (Exhibits 5 and 6). The green dashed line represents the $95 \%$ confidence intervals for the deterministic component for each series. The red circles represent negative jumps, and the blue circles represent positive jumps. 
Panel A: Interconnection between France (B) and Germany (A)

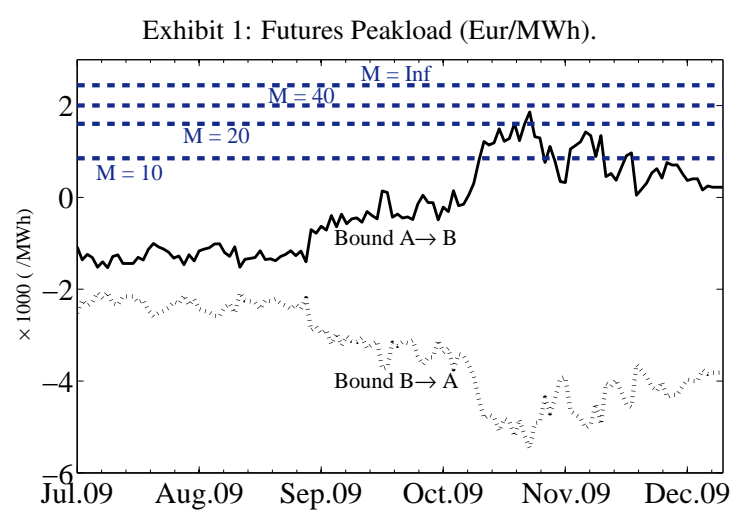

Exhibit 2: Futures Baseload (Eur/MWh)

Panel B: Interconnection between France (B) and the United Kingdom (A)
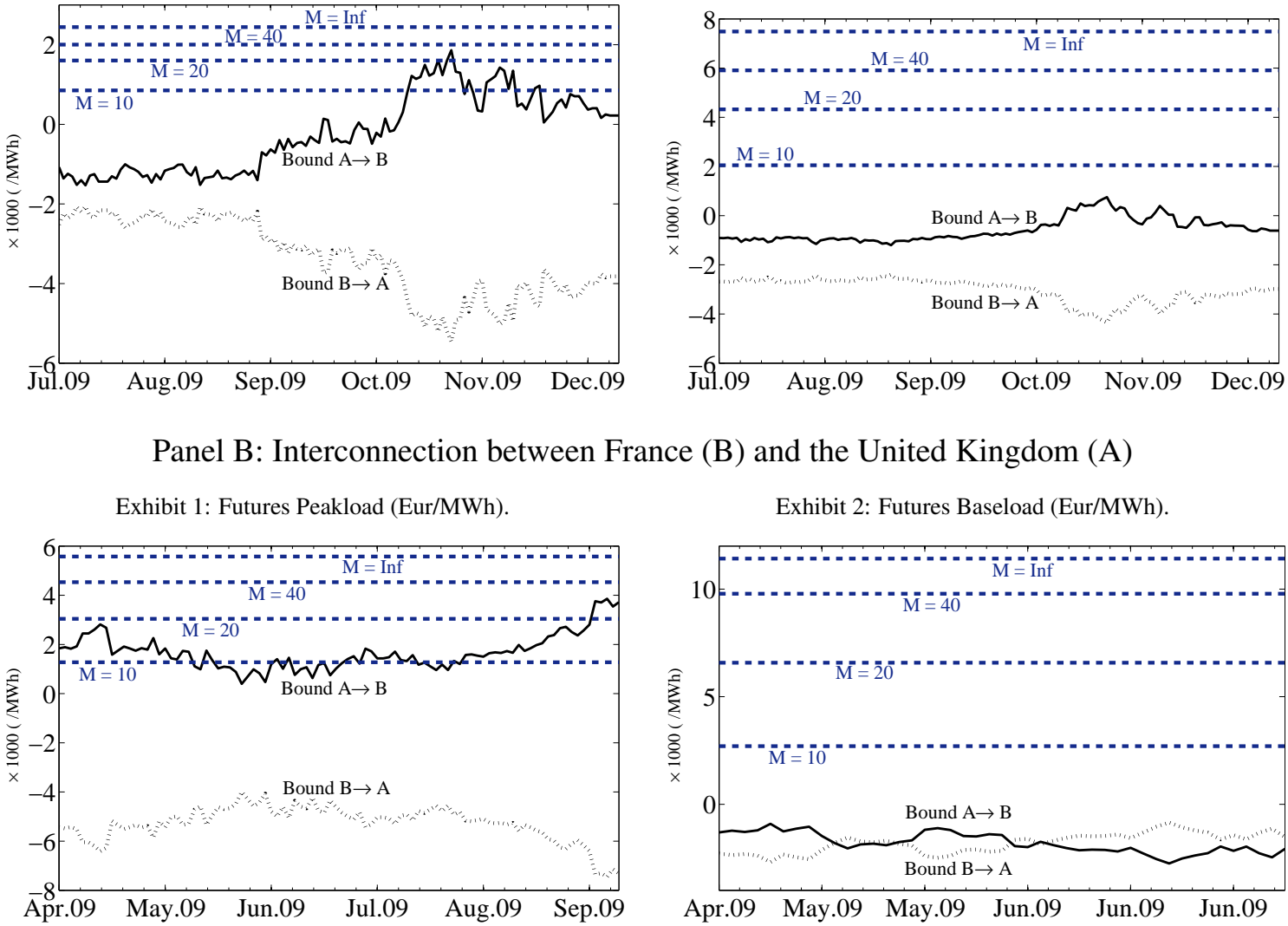

Exhibit 2: Futures Baseload (Eur/MWh).

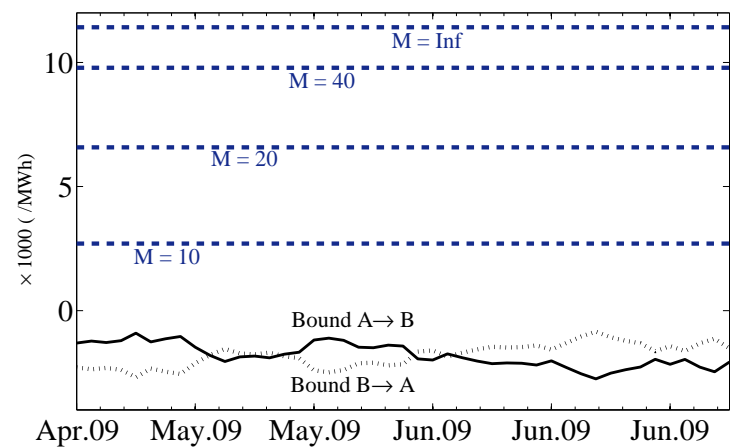

Panel C: Interconnection between Nord Pool (B) and Germany (A)

Exhibit 1: Futures Peakload (Eur/MWh).

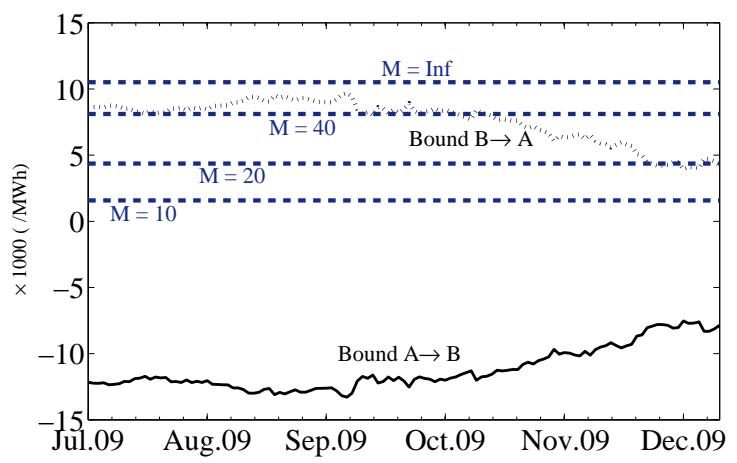

Exhibit 2: Futures Baseload (Eur/MWh).

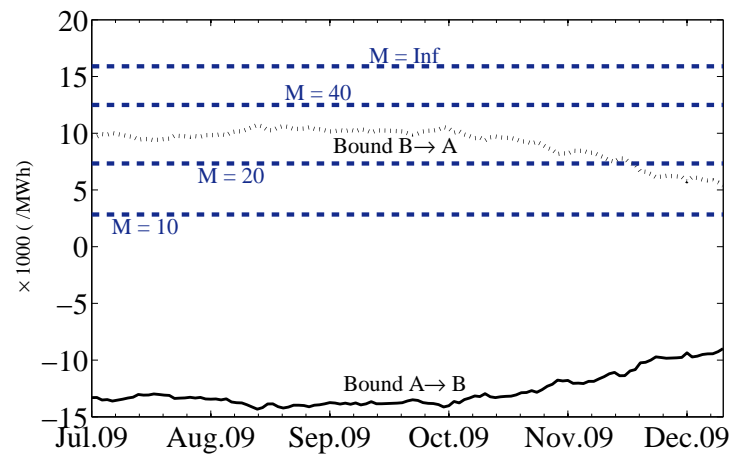

Figure 4. Empirical no-arbitrage bounds

Dashed blue lines show the corresponding interconnector value of Table 7 for different liquidity constraints $M=10,20,40$ and $\infty$. Black lines show the bounds computed from equations (11), (12), (13), (14). The no-arbitrage bounds resulting from buying a forward contract in location $\mathrm{B}$, and shorting a forward contract for location $\mathrm{A}$ (bound $\mathrm{A} \rightarrow \mathrm{B}$ ) are depicted by a solid line. Similarly, the dotted line represents the bound resulting from being long a forward contract in location $\mathrm{A}$, and short a forward in location $\mathrm{B}$ (bound $\mathrm{B} \rightarrow \mathrm{A}$ ). 